\title{
Alterations in transcription clusters underlie development of bladder cancer along papillary and nonpapillary pathways
}

\author{
Jai-Hyun Kim, Tomasz Tuziak ${ }^{1, *}$, Limei Hu, Zhi Wang ${ }^{1}$, Jolanta Bondaruk ${ }^{1}$, \\ MiSook Kim ${ }^{1}$, Gregory Fuller ${ }^{1}$, Colin Dinney ${ }^{2}$, Herbert Barton Grossman ${ }^{2}$, \\ Keith Baggerly ${ }^{3}$, Wei Zhang ${ }^{1}$ and Bogdan Czerniak ${ }^{1}$
}

${ }^{1}$ Department of Pathology, The University of Texas MD Anderson Cancer Center, Houston, TX, USA; ${ }^{2}$ Department of Urology, The University of Texas MD Anderson Cancer Center, Houston, TX, USA and ${ }^{3}$ Department of Biostatistics and Applied Mathematics, The University of Texas MD Anderson Cancer Center, Houston, TX, USA

\begin{abstract}
Bladder cancer develops in the urothelial lining from intraurothelial preneoplasia via two pathways, papillary and nonpapillary, which correspond to nonaggressive and aggressive forms of the disease. Because these two forms of cancer may develop via distinct molecular events, we examined the gene expression patterns in the development of bladder cancer from preneoplasia along papillary and nonpapillary pathways. The expression profiles of 19 pairs of RNA samples from adjacent urothelium and tumors were analyzed using cDNA microarrays. For selected genes their expressions were verified on a cohort of 251 bladder cancer patients using tissue microarray and immunohistochemistry and were related to clinicopathological parameters including follow-up data. We identified alterations in seven gene clusters controlling proliferation, differentiation, and programmed cell death that were common for papillary and nonpapillary cancer. In contrast, genes controlling cellular and stromal interactions were altered in the nonpapillary cancer. The expression levels of only two genes from this group could be used to define an aggressive form of the disease. Tumors characterized by the low expression of e-cadherin and the high expression of DNA $\alpha$-topoisomerase II had a high propensity for distant metastasis and were associated with poor survival.
\end{abstract} Laboratory Investigation (2005) 85, 532-549. doi:10.1038/labinvest.3700250

Keywords: cDNA microarray; bladder cancer; gene expression profile; tissue microarray; preneoplasia

Many common human epithelial malignancies develop by progression of microscopically identifiable precursor conditions ranging from mild dysplasia to carcinoma in situ. ${ }^{1}$ These conditions progress to clinically aggressive invasive cancer by multiple cumulative molecular events. $^{2}$ In fact, the earliest incipient changes occur in normal tissue even before preneoplastic lesions can be microscopically identified. The identification of abnormally expressed genes in such occult preneoplastic lesions may provide important clues as to the molecular pathways involved in the development of human cancer and facilitate early cancer detection and prevention.

Correspondence: Dr B Czerniak, MD, PhD, Department of Pathology, The University of Texas MD Anderson Cancer Center, Unit 085, 1515 Holcombe Blvd., Houston, TX 77030, USA.

E-mail: bczernia@mdanderson.org

*These authors contributed equally to this work.

Received 10 November 2004; revised and accepted 4 January 2005
Carcinoma of the bladder is an exceptionally good candidate for such studies representing a model epithelial malignancy, which develops from microscopically recognizable intraurothelial preneoplastic lesions. ${ }^{2-4}$ The fifth most frequent human cancer, it primarily affects people over the age of 50 years, and accounts for approximately $3 \%$ of all cancerrelated deaths. ${ }^{5}$ The common bladder carcinomas arise via two distinct, but sometimes overlapping pathways, papillary and nonpapillary. ${ }^{6-9}$ Approximately $80 \%$ of bladder tumors are superficially growing lesions that originate from urothelial hyperplasia. They frequently recur after excision but usually do not aggressively invade the bladder wall or metastasize. Most aggressive bladder cancers are of the solid, nonpapillary type and originate from intraurothelial precursor conditions such as dysplasia and carcinoma in situ. They aggressively invade the bladder wall and have a high propensity for distant metastasis. 
In this paper, we describe the gene expression profile of bladder cancer as it develops from preneoplastic conditions via papillary and nonpapillary pathways. We used cDNA microarrays to identify abnormally expressed genes in the preneoplastic intraurothelial phase of bladder cancer and disclosed distinctive gene clusters abnormally expressed in both pathways as well as those signifying the onset of invasive disease. For selected genes, the expression profile was tested by immunohistochemistry in bladder tumor tissue microarrays in relation to the pathological parameters of tumors and clinical follow-up data.

\section{Material and methods}

\section{Tissue Samples}

Tumor samples and follow-up data were collected and archived according to the laboratory protocol approved by the Institutional Review Board of The University of Texas MD Anderson Cancer Center. All patients had primary urothelial carcinomas of the bladder, and none of the patients whose tumor samples were used in this study received prior chemotherapy or radiotherapy. The gene expression profiles in 19 pairs of RNA samples obtained from adjacent urothelium and bladder tumors were analyzed with cDNA microarrays. The patients ranged from 49 to 81 years in age (mean, 69 years), 14 patients were men and 5 were women. The baseline gene expression profile was obtained using RNA of normal urothelium derived from ureters without evidence of urothelial neoplasia excised for other medical reasons. Each fresh cystectomy specimen was opened longitudinally along the anterior wall of the bladder and pinned down to a paraffin block. One representative section from the central area of grossly identified tumor was removed, cut into small pieces, and transferred to a conical tube containing $5 \mathrm{ml}$ PBS. The tube was mechanically agitated for 5 min using a vortex mixer to release the tumor cells. The presence of the tumor in the tissue was confirmed by microscopic analysis of a parallel frozen section stained with hematoxylin-eosin. Cell suspensions of urothelium adjacent to tumors were prepared by mechanical scraping of the mucosal surface with a razor blade. First, a selected adjacent mucosal area was marked with India ink and its surface urothelium was scraped with a razor blade. Multiple histologic sections of the scraped area were submitted for microscopic examinations to rule out contamination with invasive tumor or with grossly occult microscopic papillary lesions. The samples were then transferred to conical tubes containing PBS, and their purity was determined by cytological examinations of cytospin preparations. Only those samples that yielded more than 90\% microscopically recognizable intact normal, dysplastic or tumor cells were used for RNA extraction.
For selected up- and down-regulated genes identified by cDNA microarrays, expression profiles were verified by immunohistochemistry using a tissue microarray, that contained samples of 251 bladder tumors related to patient follow-up data. The tumors were classified according to the threetier World Health Organization (WHO) histological grading system and growth pattern (papillary vs nonpapillary). ${ }^{10}$ The depth of invasion was recorded according to the tumor-node-metastasis (TNM) staging system. ${ }^{11}$ Stage $\mathrm{T}_{1}$ (lamina propria invasion) has been divided into $\mathrm{T}_{1 \mathrm{a}}$ (no muscularis mucosae invasion) and $\mathrm{T}_{1 \mathrm{~b}}$ (muscularis mucosae invasion), which has a significantly higher risk of progression. ${ }^{12}$ So, as in our previous publications, the tumors were dichotomized into superficial $\left(\mathrm{T}_{\mathrm{a}}-\mathrm{T}_{1 \mathrm{a}}\right)$ and invasive ( $\mathrm{T}_{1 \mathrm{~b}}$ and higher) groups. ${ }^{13}$

\section{cDNA Microarray Assay}

For extraction of RNA, tissue samples were placed immediately in TRIzol reagent (Invitrogen, Carlsbad, CA, USA) and homogenized using a PowerGen 125 tissue homogenizer (Fisher Scientific, Pittsburgh, PA, USA). Total RNA was isolated using the TRIzol reagent protocol. The quality of the RNA was evaluated by RNA gel electrophoresis. The hybridization experiments including cDNA synthesis, labeling, and hybridization were carried out as previously described. ${ }^{14,15}$ Briefly, $1 \mu \mathrm{g}$ aliquots of total RNA corresponding to six samples of normal urothelium and 19 pairs of bladder tumors and their adjacent urothelium were used for cDNA synthesis using a $\mathrm{dT}_{25}-\mathrm{T} 7$ primer. The cDNA products were used for antisense RNA (cRNA) amplification by T7 in vitro transcription (Ambion, Inc., Austin, TX, USA). The pairs of aliquots containing $5 \mu \mathrm{g}$ of amplified cDNA from each sample were labeled with Cy3-dCTP and Cy5-dCTP by reverse transcription using a random hexamer (Amersham Pharmacia Biotech, Piscataway, NJ, USA). The slides were hybridized with the labeled cDNA using ExprssHyb solution (Clontech, Palo Alto, CA, USA), which contained poly $\mathrm{dA}_{(40-60)}$ (Amersham Pharmacia Biotech), yeast tRNA (GIBCO-BRL, Gaithersburg, MD, USA) and human Cot I DNA (GIBCO-BRL). Hybridization was carried out at $60^{\circ} \mathrm{C}$ for $14-16 \mathrm{~h}$, and the arrays were scanned at $20 \mu \mathrm{m}$ resolution on a GeneTAC ${ }^{\mathrm{TM}}$ LSIN scanner (Genomic Solutions, Ann Arbor, MI, USA). (Detailed information on the fabrication of the cDNA microarray used in this study can be obtained from http://www. mdanderson.org/ genomics.) A total of 2142 known human cDNAs were prepared by PCR from the Research Genetics cDNA clone library using the two primers, purified using MultiScreen PCR plates (Millipore Corp., Bedford, MA, USA), and verified by sequencing before printing. ${ }^{16}$ The DNA clones, in 384-well plates, were spotted onto 
poly-L-lysine-coated microscope slides using an arrayer (Genomic Solutions).

\section{cDNA Microarray Data Processing and Analysis}

Data processing including scanning, imaging, quantification, normalization, and quality control were performed as described previously. ${ }^{17}$ Briefly, all of the images were quantified in ArrayVision ${ }^{\text {TM }}$ (Imaging Research, St Catharines, ON, Canada); the quantification files for each array contained foreground and background measurements for each spot in each channel. After local background correction, the intensities of both channels were normalized to the 75th percentile, which was set to 1000 . Values below a threshold of 25 were set to 25 to reduce noise, and all intensity values were $\log _{2}$ transformed. Genes differentially expressed in bladder tumors vs normal urothelium or urothelium adjacent to tumors were identified through the application of a series of filters. Genes whose expressions were consistently changed in the same direction were identified by $t$-tests with a significance level of $\alpha=0.05$ after a Bonferroni adjustment. To focus on those genes whose differences in expression were largest, we retained only those where the corresponding average fold change was $>2$. To identify functionally related groups of genes, we performed hierarchical clustering of both the genes and the samples using Euclidean distance and complete linkage; functions were assessed using Fisher's exact test and gene membership defined in GeneOntology.

\section{Quantitative Real-Time RT-PCR}

To verify the cDNA microarray data, the expression levels for selected upregulated and downregulated genes were analyzed by quantitative real-time reverse transcription polymerase chain reaction (RT-PCR). The cDNA samples corresponding to the six samples of normal urothelium and the 19 pairs of bladder tumor and adjacent urothelium analyzed by cDNA microarrays were synthesized using TaqMan RT reagents (Applied Biosystems, Foster City, CA, USA) and used as templates for quantitative realtime RT-PCR. The primers and fluorescence probes for data binding protein 3 (GATA3); wingless-type MMTV integration site family, member $5 \mathrm{~A}$ (WNT5A); vasoactive intestinal peptide receptor 1 (VIPR1); e-cadherin (CDH1); metalloproteinase 7 (MMP7); dual-specificity phosphatase (DUSP5); tumor necrosis factor-alpha-induced protein 3 (TNF A1P3); lipocalin 2 (LCN2); collagen, type VI, alpha-3 (COL6A3); plasminogen activator tissue (PLAT); DNA $\alpha$-topoisomerase II (TOP2A); placktrin homology-like domain family A number 1 (PHIL$D A 1)$; lumican (LUM); collagen, type III, alpha-1 (1COL3A1); cell division cycle 2 (CDC2); carcinoembryonic antigen-related cell adhesion molecule 6 (CEACAM6); collagen, type I, alpha-2 (COL1A2); fibronectin ( $F N 1$ ); runt-related transcription factor 2 (OSF2); and metalloproteinase 12 (MMP12) were designed according to the Assays-by-Design Service provided by Perkin-Elmer/Applied Biosystems. To avoid amplification of the residual genomic DNA, the primers flanking the sequences for amplifications were located in different exons. The amplifications were carried out in a Perkin-Elmer/Applied Biosystems 7700 Prism using the following temperature profile: denaturation at $95^{\circ} \mathrm{C}$ for $15 \mathrm{~s}$, annealing and extension at $60^{\circ} \mathrm{C}$ for $1 \mathrm{~min}$. Amplifications were performed in duplicates for each gene, and 18S rRNA was used as an internal control to normalize the quantity of cDNA. Expression levels of each gene were calculated relative to their expression levels in normal urothelium.

\section{Tissue Microarray and Immunohistochemistry}

Immunohistochemical studies were performed on two distinct sets of formalin-fixed paraffinembedded tissue samples using the avidin-biotin peroxidase complex method. ${ }^{18}$ First, they were

\footnotetext{
Figure 1 Two-way hierarchical clustering and multidimensional scaling analysis of gene expressions from 19 pairs of tumor and adjacent urothelium. (a) Two-way clustering analysis diagram of transcript ratios for 19 paired samples of tumors and adjacent urothelium based on a 2,142-gene set. Each row in the diagram represents a gene and each column represents a bladder tumor or adjacent urothelium sample. Ratios of gene expression relative to normal urothelium samples are shown as the color saturation scale at the bottom of diagram. Genes with lower levels of expression as compared to normal urothelium samples are shown in green. Genes with higher expression than normal urothelium are shown in red. Genes with expression levels similar to normal urothelium are printed in black. The dendrogram on the left side of the diagram represents the clusters of functionally related genes. The paired samples corresponding to tumor and adjacent urothelium are grouped at the top according to their pathogenetic subset representing low-grade (Grade 1-2) superficial papillary TCC and high-grade (Grade 3) invasive TCC. The continuous lines on the right side of the diagram depict the mean expression levels for individual gene clusters calculated separately for urothelium adjacent to low-grade superficial papillary TCC (AU LG TCC-crimson), urothelium adjacent to high grade TCC (AU HG TCC-blue), low-grade TCC samples (LG TCC_-gray), and high-grade TCC samples (HG TCC-orange). The thick bars on the right side of the diagram denote clusters of functionally related genes that were differentially expressed in adjacent urothelium and tumor samples as compared to the normal urothelium (clusters 1-7). (b) Cluster diagram of 19 paired samples of tumor and adjacent urothelium based on analysis of transcript ratios for 34 differentially expressed genes. Paired samples are consecutively labeled 1-19. Histologic grade and stage for each tumor are also provided. The presence of severe dysplasia/ carcinoma in situ (CIS) is indicated in adjacent urothelium samples. AU, adjacent urothelium, TCC, corresponding paired tumor samples. (c) A two-dimensional principal component plot of 19 paired samples of bladder tumor and adjacent urothelium based on the analysis of transcript ratio for 34 differentially expressed genes.
} 
a

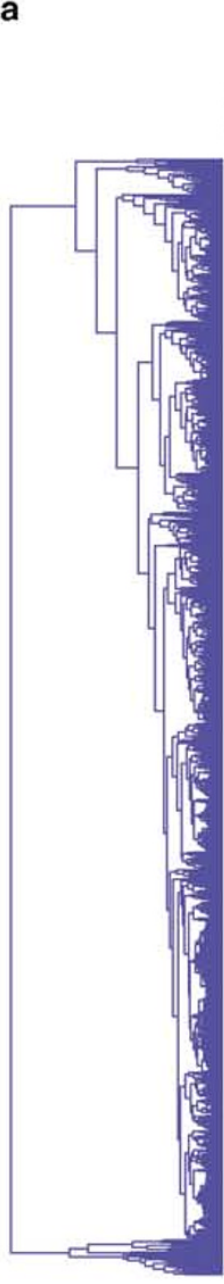

\begin{tabular}{|c|c|c|c|c|}
\hline \multicolumn{2}{|c|}{$\begin{array}{l}\text { Low Grade } \\
\text { TCC }\end{array}$} & \multicolumn{3}{|c|}{$\begin{array}{l}\text { High Grade } \\
\text { TCC }\end{array}$} \\
\hline$A U$ & TCC & $A U$ & CIS & TCC \\
\hline
\end{tabular}

- AU LG TCC

- AU HG TCC

- LG TCC
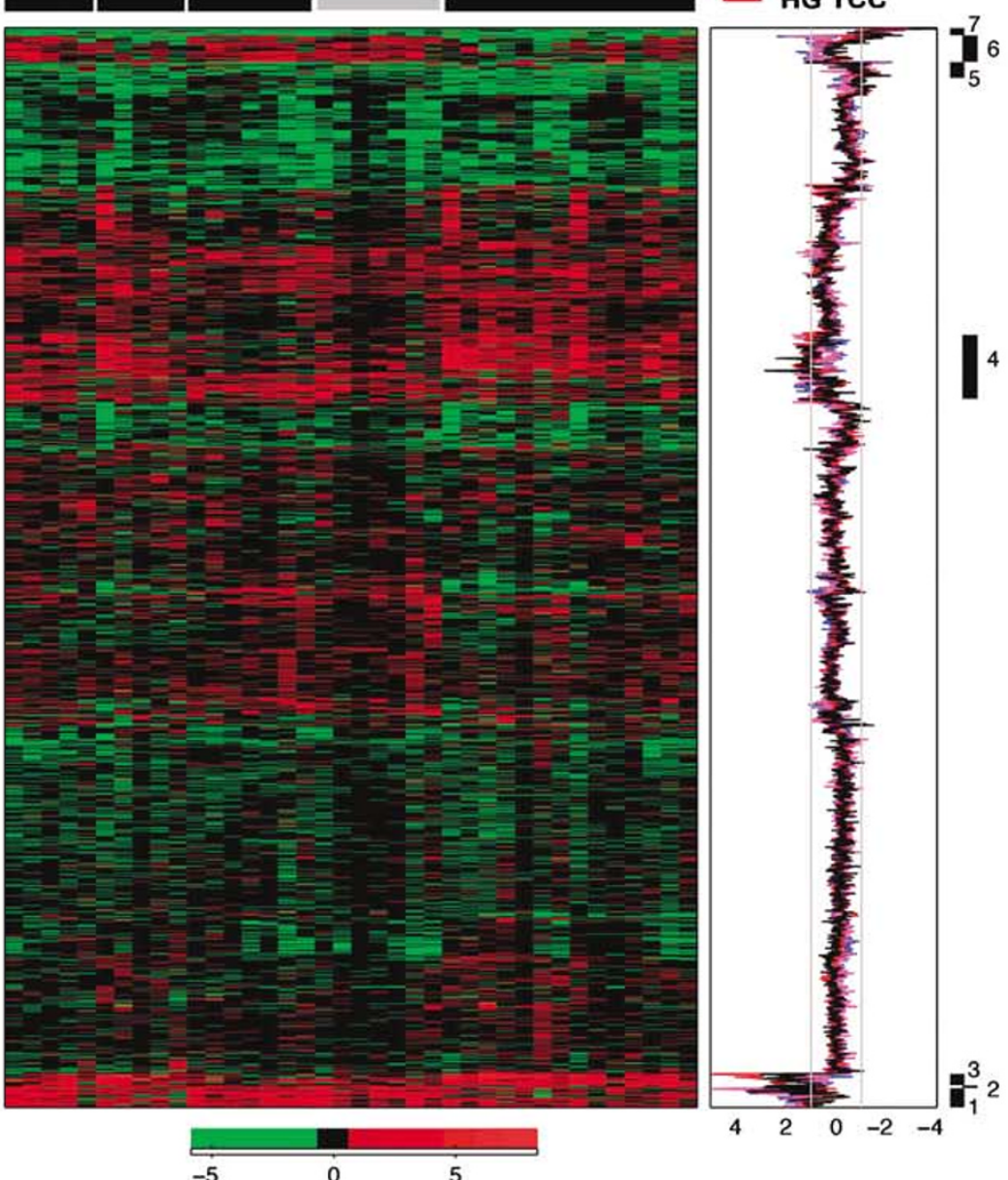
performed on parallel sections corresponding to adjacent urothelium and tumors from which RNA was extracted for cDNA microarray analysis. Second, they were performed on tissue microarray containing 251 bladder tumors related to their corresponding clinico-pathologic data including follow-up.

For the confirmation of cDNA microarray data and quantitative real-time PCR results, $2 \mu \mathrm{m}$ tissue sections of the tumor and adjacent urothelium were deparafinized, rehydrated, and pretreated with Tris buffer $\left(\mathrm{pH}\right.$ 8) at $99^{\circ} \mathrm{C}$ for $45 \mathrm{~min}$. Endogenous peroxidase activity was quenched using $0.3 \% \mathrm{H}_{2} \mathrm{O}_{2}$ in $90 \%$ methanol for $5 \mathrm{~min}$ and stained with the following antibodies: e-cadherin (CDH1), 1:20, Zymed (South San Francisco, CA, USA); fibronectin (FN1), 1:100, Oncogene Sciences (Boston, MA, USA); topoisomerase DNA II alpha (TOP2A), 1:100, Oncogene Sciences (Boston, MA, USA); cell division cycle 2 (CDC2), 1:150, Oncogene Sciences (Boston, MA, USA); metalloproteinase 7 (MMP7), 1:150, R\&D Systems (Minneapolis, MN, USA); metalloproteinase 12 (MMP12), 1:100, R\&D Systems (Minneapolis, MN, USA); parvalbumin (PVALB), 1:2000, Sigma (St Louis, MO, USA); collagen III (COLA3A1), 1:50, Oncogene Sciences (Boston, MA, USA) for $1 \mathrm{~h}$ at room temperature. The bound primary antibodies were visualized by avidin- biotin complex assay (DAKO Corp, Carpenteria, CA, USA) with 3,3'-diaminobenzidine as a chromogen (DAKO) and hematoxylin as a counterstain. Sections of normal urothelium from ureters of nephrectomy specimens without evidence of urothelial neoplasia were used as positive controls. Sections incubated with secondary reagents only served as negative controls. Both negative and positive controls were included in all runs. The intensity of staining was visually evaluated and compared to the level of staining in sections of normal ureters.

The tissue microarray was assembled as previously described..$^{19,20}$ In brief, histologic slides from 251 bladder cancers were reviewed and the most representative, well-preserved areas of the tumor tissue were selected and marked. The donor paraffin blocks were punched in areas of interest using a microarray instrument (Beecher Instruments, Inc., Sun Prairie, WI, USA) and $0.6 \mathrm{~mm}$ cores of the tumor tissue were transferred to a recipient block. The recipient microarray block contained 85 noninvasive low-grade (Grade 1-2) papillary carcinomas, 26 noninvasive high-grade (Grade 3) papillary carcinomas, and 140 invasive high-grade (Grade 3) nonpapillary carcinomas. Overall, the microarray contained 111 superficial $\left(\mathrm{T}_{\mathrm{a}}-\mathrm{T}_{1 \mathrm{a}}\right)$ and 140 invasive $\left(\mathrm{T}_{1 \mathrm{~B}}\right.$ and higher) transitional cell carcinomas of the bladder.

For immunohistochemical staining $2 \mu \mathrm{m}$ tissue sections of the recipient microarray block were stained with the following primary antibodies: e-cadherin $(C D H 1)$, fibronectin $(F N 1)$, topoisomerase DNA II alpha (TOP2A), cell division cycle 2 (CDC2), metalloproteinase 7 (MMP7), metalloproteinase 12 (MMP12), parvalbumin (PVALB), and collagen III (COLA3A1) using the same concentrations and protocol as described above.

\section{Tissue Microarray Data Processing and Analysis}

The staining intensity of each antigen in the tissue microarray was measured using an automated scanner GenoMx (Automated Digital Image System, Bio Genex, San Ramon, CA, USA) following the manufacturer's recommendations. The area of tumor was outlined in each tissue core, and its staining intensity was compared to the intensity of staining in normal urothelium for each protein. For each tumor sample, the relative expression level (REL) of a gene was calculated as follows: REL $=P \times(M+H)$, where $P$ was the area of the tumor with positive staining (\%), $M$ was the area of the tumor with medium staining intensity, and $H$ was the area of the tumor with high staining intensity. The tumors were divided into two groups, that is, those with REL scores above and below the median value for each gene.

The relationship between expression levels of genes and various clinicopathologic parameters was analyzed using two-sample $t$-tests and Wilcoxon's rank sum test. Measures were analyzed both with and without logarithmic transformation with similar results in both. The nonparametric and parametric tests were in qualitative agreement throughout.

The expression levels of individual genes in relation to the time between diagnosis and recurrence, to the time between diagnosis and metastasis, and to overall survival were examined with Kaplan-Meier plots and tested for significance with log-rank tests.

Univariate Cox proportional hazard models were used to assess the relation of each gene's expression level to time between diagnosis and recurrence, to time between diagnosis and metastasis, and to overall survival. Finally, the expression levels for each gene were analyzed with multivariate Cox proportional hazard models, which included such

\footnotetext{
Figure 2 Expanded view of gene cluster 4 differentially expressed in TCC and adjacent urothelium. The examples of differentially expressed gene cluster based on more than a two-fold change in adjacent urothelium (AU) and tumor (TCC) as compared to normal urothelium. The genes in these clusters were filtered with the Wilcoxon rank sum and $t$-tests. This cluster contain genes encoding nuclear transcription factors, gene involved in mediation of immune response, and genes related to cell-cycle regulation. The color scale of gene expression level is depicted in Figure 1. A complete list of genes (clusters 1-7) differentially expressed in TCC and adjacent urothelium is submitted as supplemental material.
} 


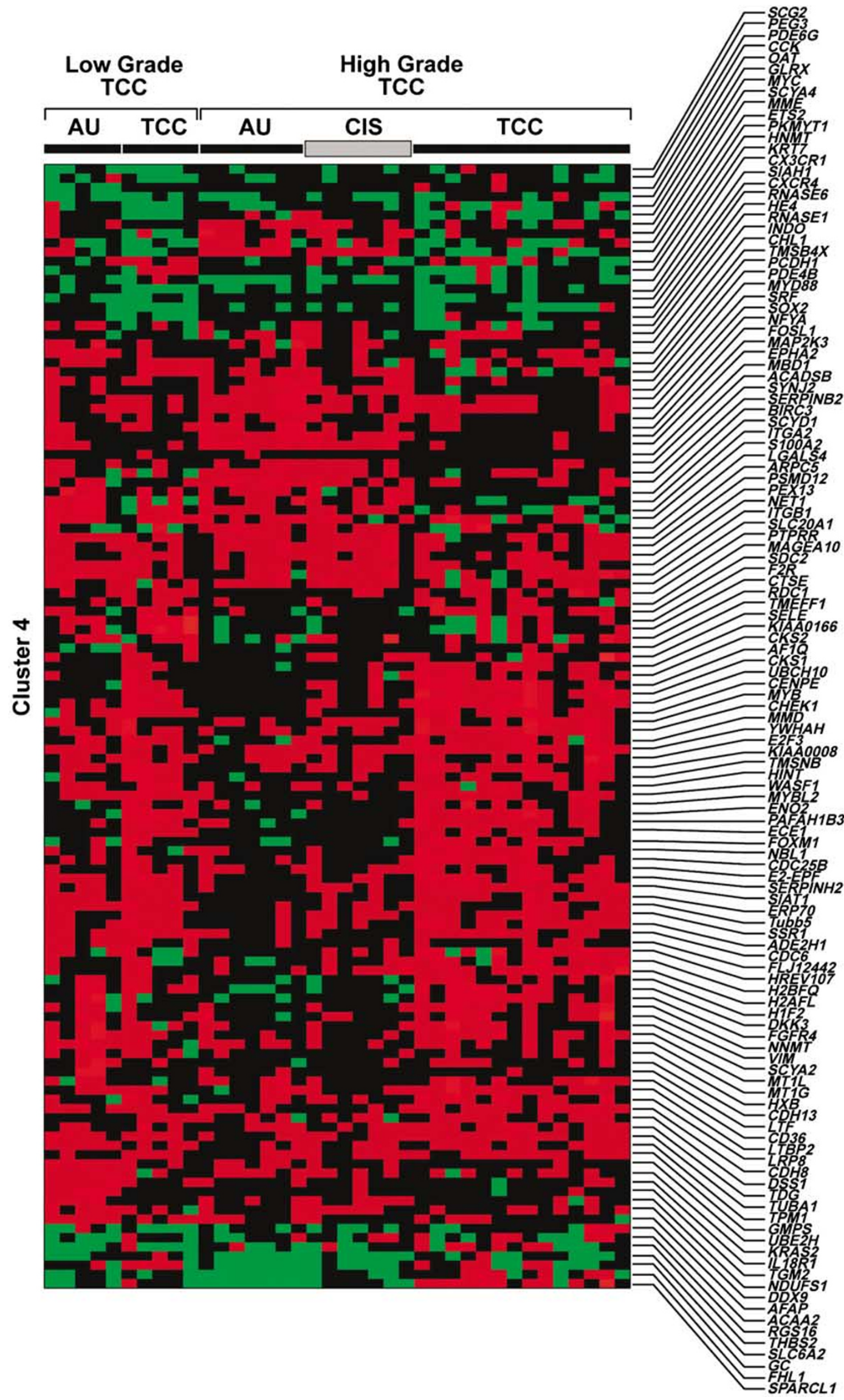


clinicopathological parameters as histologic grade, growth pattern, and stage as covariates.

\section{Results}

\section{Gene Expression Profiles of Papillary and Nonpapillary Bladder Cancer}

To identify abnormally expressed genes that are potentially involved in the development of bladder cancer, we tested 19 pairs of tissue samples taken from tumor and adjacent urothelium and compared their gene expression patterns to six samples of normal urothelium. These analyses identified 193 and 166 genes with abnormal expression in tumors and urothelium adjacent to tumors, respectively. A two-dimensional hierarchical analysis identified seven distinct clusters of genes that were differentially expressed in tumors and their adjacent urothelium as compared with normal urothelium (Figure 1a). Their alterations underlie the development of bladder cancer from intraurothelial preneoplastic conditions regardless of histologic grade and growth pattern, because in general the gene expression profile was similar in low-grade papillary and high-grade nonpapillary pathways. In fact, we could not separate the pathogenetic subsets of bladder tumors such as papillary vs nonpapillary and low-grade (Grade 1-2) vs high-grade (Grade 3) using clustering analysis of all abnormally expressed genes. In contrast, we could separate tumors and their adjacent urothelium based on cluster analysis using 34 differentially expressed genes (Figure $1 \mathrm{~b}$ and $\mathrm{c}$ ).

The seven clusters contained primary transcription regulators of key cellular functions. Genes in clusters 1 through 3 , which were highly overexpressed in adjacent urothelium and tumors, encode proteins involved in apoptosis and cellstroma interactions. Cluster 4 genes, which were also overexpressed in adjacent urothelium and tumors, encode nuclear transcription factors, genes involved in mediation of immune response, genes related to cell-cycle regulation, and genes involved in angiogenesis such as fibroblast growth factor receptors namely FGFR4. Downregulated genes related to stress response and cell differentiation formed cluster 5. Cluster 6 contained upregulated genes encoding major histocompatibility complexrelated proteins, while cluster 7 genes, encoded proteins with unspecified functions, which were downregulated in tumors and their adjacent urothelium. Expanded view of gene cluster 4 is provided in Figure 2. A complete list of genes and their relative expression levels for each cluster are provided in the supplemental material.

Since low-grade papillary and high-grade nonpapillary invasive TCCs are postulated to arise via distinct molecular mechanisms, we attempted to identify genes that were differentially expressed in these two groups of tumors. We found a cluster of 68 genes primarily coding for proteins regulating cellular-stromal interactions (Figure 3). In general, clinically aggressive, invasive, nonpapillary tumors were characterized by upregulation of genes coding for proteases responsible for degradation of stromal elements such as cellular metalloproteinase 7 (MMP7), metalloproteinase 12 (MMP12), and cathepsin E (CTSE) and genes involved in the promotion of invasive growth such as fibronectin (FN1) and downregulation of cell adhesion molecules such as cadherins $(C D H)$.

The elevated expression levels of genes related to ras pathway were present in cluster 4 and in a list of 34 genes differentially expressed in tumors and normal urothelium. These included $v$-Ki-ras2 Kirsten rat sarcoma 2 viral oncogene homolog (KRAS2), mitogen-activated protein kinase $3(M A P 2 K 3)$, and member RAS oncogene family (RAB9). In addition, $M A P 2 K 3$ was overexpressed in clinically aggressive high-grade invasive nonpapillary tumors.

To validate gene expression data obtained with cDNA microarrays, we performed quantitative realtime RT-PCR and immunohistochemical studies for selected up- and down-regulated genes using the same pairs of tumor and adjacent urothelium RNA samples. The levels of gene expression obtained by real-time RT-PCR were compared to the baseline levels in normal urothelium (Figure 4a). In general, the real-time RT-PCR and immunohistochemical study results were similar to the results obtained with cDNA microarrays. However, several upregulated genes coding for proteins that are typically not expressed in epithelial cells such as collagens appeared. This overexpression might have resulted from contamination of urothelial or tumor cell samples with nontumor stromal components. In fact, the immunohistochemical stains of parallel sections from tumors used for cDNA microarrays showed that the upregulation of genes coding for collagens did not occur in tumor cells but in the adjacent stromal tissue (Figure $4 \mathrm{~b}$ ).

\footnotetext{
Figure 3 Two-way hierarchical clustering and principal component analysis of selected genes differentially expressed in low-grade (Grade 1-2) superficial $\left(\mathrm{T}_{\mathrm{a}}-\mathrm{T}_{1 \mathrm{a}}\right)$ TCC and high-grade (Grade 3) invasive $\left(\mathrm{T}_{1 \mathrm{a}}-\mathrm{T}_{4}\right)$ TCC. (a) Two-way clustering analysis diagram of transcript ratios for 19-paired samples of adjacent urothelium (AU) and tumors (TCC) using 68 genes differentially expressed in lowgrade superficial TCC and high-grade invasive TCC. Ratios of gene expression in TCCs relative to normal urothelium are shown as the color saturation scale as depicted in Figure 1. The dendrogram on the left side of the diagram represents the clusters of functionally related genes. Samples are designated at the top of the diagram as in Figure 1. (b). A two-dimensional principal component plot of 19 pairs of tumor samples and adjacent urothelium corresponding to low-grade superficial papillary and high-grade invasive TCCs based on the ratio for 68 differentially expressed genes.
} 
a

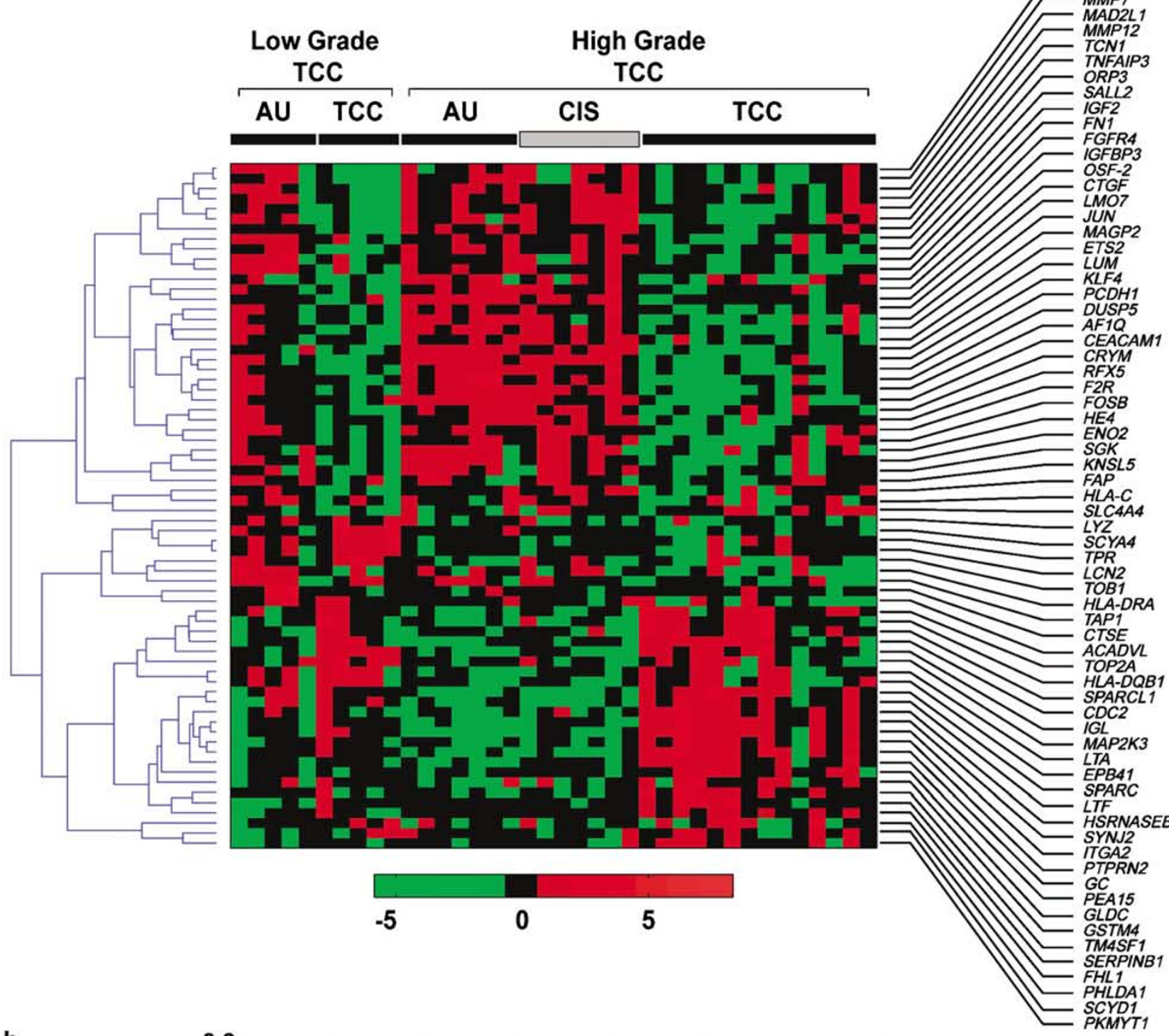

b

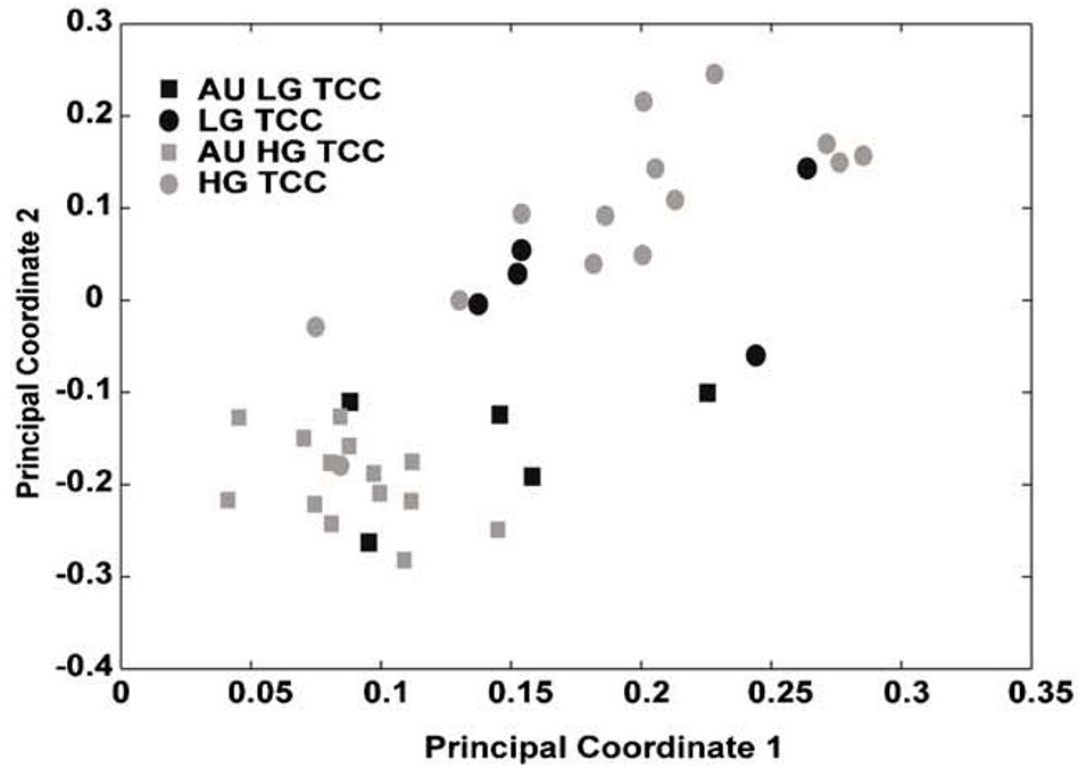




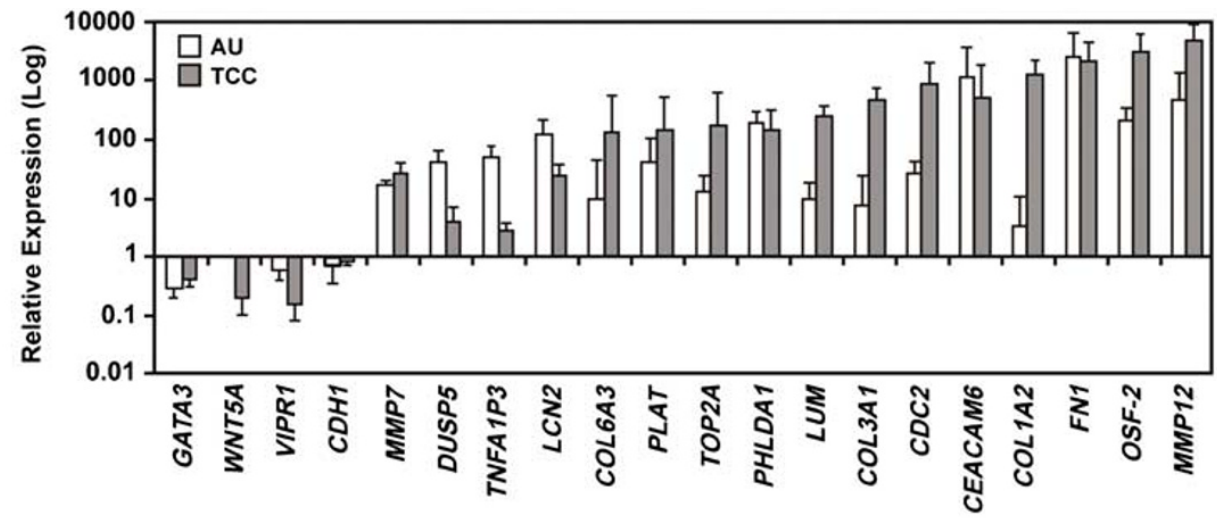

b
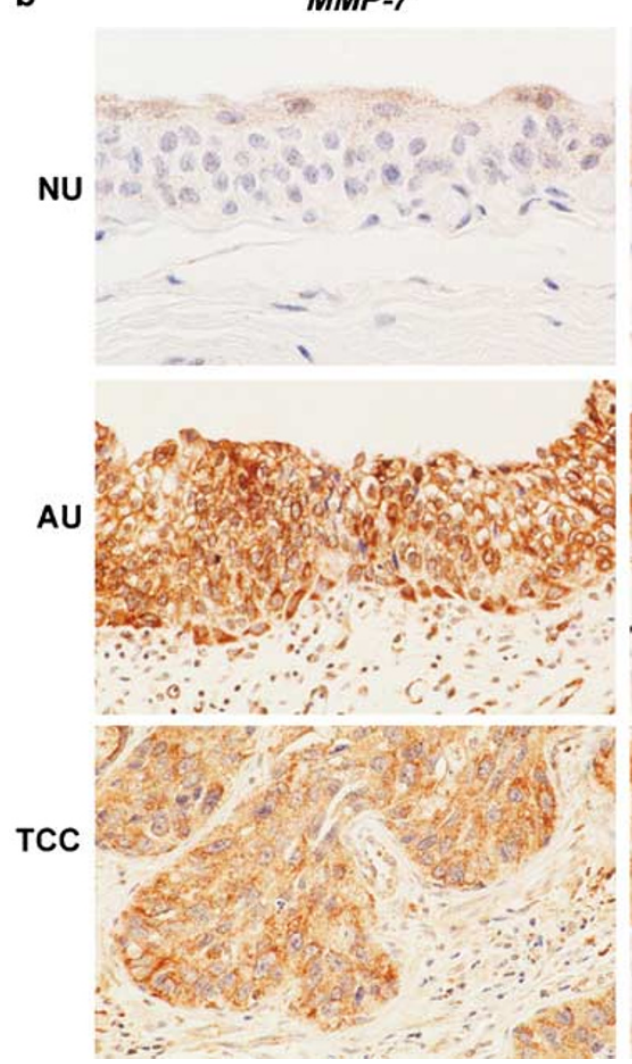

$C D C-2$
COL3A2
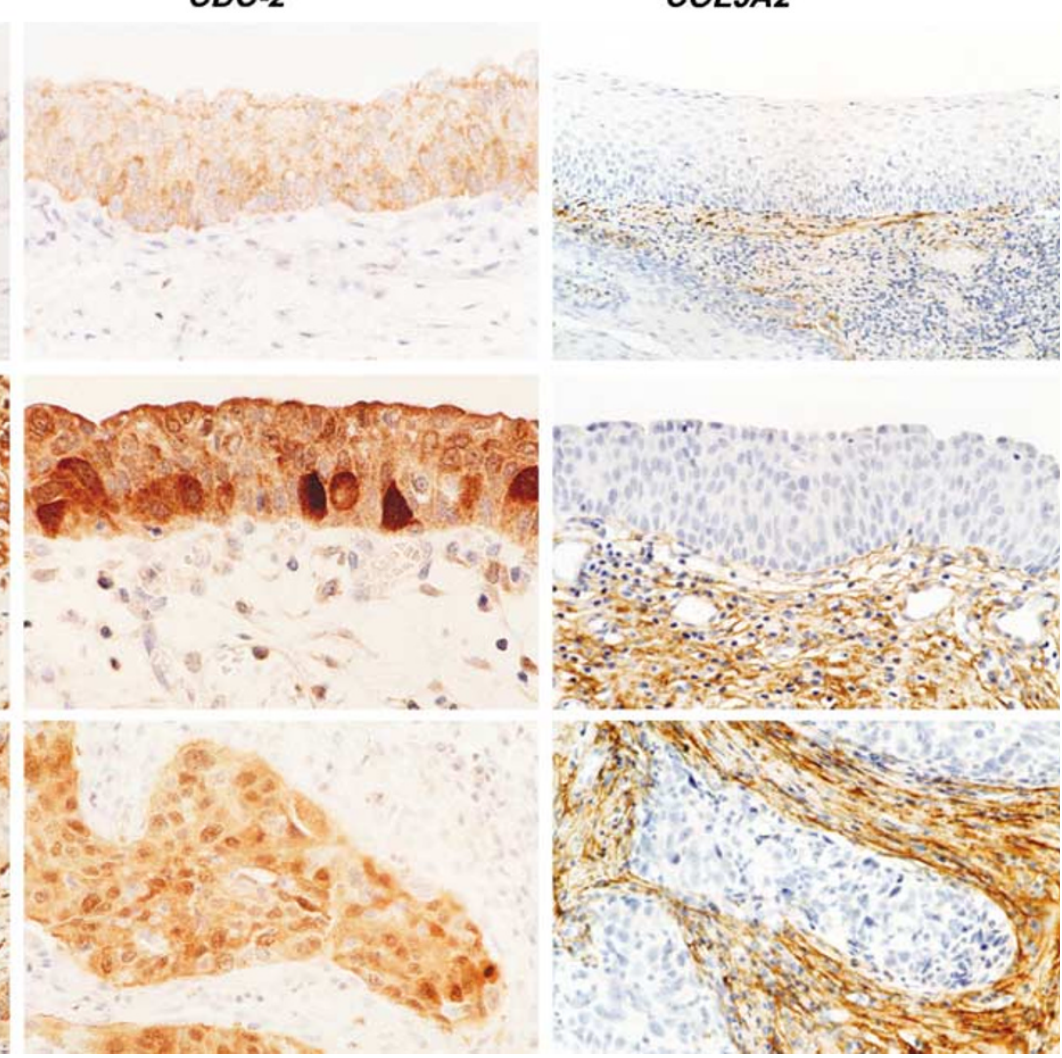

Figure 4 Verification of cDNA microarray data by quantitative real-time PCR and immunohistochemistry. (a) The expression levels of selected genes tested on the same paired RNA samples corresponding to TCC and adjacent urothelium were used for the cDNA microarray analysis. The relative expression levels represent comparisons between tested samples and normal urothelium. (b) Examples of expression patterns for metalloproteinase 7 (MMP7), cell division cycle 2 (CDC2), and collagen III (COL3A2) revealed by immunohistochemical staining of histologic sections corresponding to normal urothelium (NU), urothelium adjacent to TCC (AU), and invasive TCC. Note increased expression levels of MMP7 and CDC2 in adjacent urothelium and TCC as compared to NU. Severe overexpression of collagen III is seen within the stroma surrounding clusters of invading tumor cells and underneath the adjacent urothelium. No expression of collagen III could be detected in the tumor cells.

\section{Validation of Six Proteins Defining Aggressive Bladder Cancer}

Finally, we selected six genes: DNA $\alpha$-topoisomerase II (TOP2A), cell division cycle 2 (CDC2), MMP7, $M M P 12, F N 1$, and e-cadherin ( $C D H 1)$ that displayed major differences in mRNA levels between lowgrade (Grade 1-2) superficial papillary tumors and high-grade (Grade 3) invasive carcinomas for com- parisons to immunohistochemical results and clinical follow-up data (Table 1). Overexpression of FN1 and $C D C 2$ correlated with high histologic grade and invasive phenotype while overexpression of TOP $2 \mathrm{~A}$ and MMP12 correlated with high histologic grade but not with invasion (Table 1). The strongest association was detected for downregulation of $C D H 1$, which was associated with a nonpapillary growth pattern, high histologic grade, and 
Table 1 Relationship between expression of six genes and pathologic features of 251 bladder cancers

\begin{tabular}{|c|c|c|c|c|c|c|c|c|c|c|c|c|}
\hline & \multicolumn{2}{|c|}{$\mathrm{CDH1}$} & \multicolumn{2}{|c|}{ FN1 } & \multicolumn{2}{|c|}{ TOP2A } & \multicolumn{2}{|c|}{$C D C-2$} & \multicolumn{2}{|c|}{$M M P 7$} & \multicolumn{2}{|c|}{$M M P 12$} \\
\hline & $R E L^{\mathrm{a}}$ & $\mathrm{P}^{\mathrm{b}}$ & $R E L^{\mathrm{a}}$ & $\mathrm{P}^{\mathrm{b}}$ & $R E L^{\mathrm{a}}$ & $\mathrm{P}^{\mathrm{b}}$ & $R E L^{\mathrm{a}}$ & $\mathrm{P}^{\mathrm{b}}$ & $R E L^{\mathrm{a}}$ & $\mathrm{P}^{\mathrm{b}}$ & $R E L^{\mathrm{a}}$ & $\mathrm{P}^{\mathrm{b}}$ \\
\hline Growth pattern & & $(<0.001)$ & & $(0.080)$ & & $(0.971)$ & & $(0.062)$ & & $(0.904)$ & & $(0.152)$ \\
\hline Papillary & $72.5 \pm 1.9$ & & $16.7 \pm 1.3$ & & $5.9 \pm 0.4^{\mathrm{c}}$ & & $14.3 \pm 1.0$ & & $53.9 \pm 1.7$ & & $13.6 \pm 1.0$ & \\
\hline Nonpapillary & $38.4 \pm 2.1$ & & $21.4 \pm 1.5$ & & $5.7 \pm 0.4$ & & $16.5 \pm 1.0$ & & $53.7 \pm 1.6$ & & $16.7 \pm 1.2$ & \\
\hline Histologic grade ${ }^{\mathrm{d}}$ & & $(<0.001)$ & & $(0.002)$ & & $(<0.001)$ & & $(0.001)$ & & $(0.447)$ & & $(0.012)$ \\
\hline Low (Gr. 1-2) & $82.0 \pm 1.6$ & & $13.7 \pm 1.3$ & & $3.8 \pm 0.3$ & & $13.5 \pm 1.2$ & & $52.0 \pm 1.6$ & & $12.8 \pm 1.0$ & \\
\hline High (Gr. 3) & $43.0 \pm 2.1$ & & $21.1 \pm 1.4$ & & $6.7 \pm 0.4$ & & $16.3 \pm 1.0$ & & $54.7 \pm 1.6$ & & $16.3 \pm 1.1$ & \\
\hline Stage $^{\mathrm{c}}$ & & $(<0.001)$ & & $(0.004)$ & & $(0.134)$ & & $(0.038)$ & & $(0.298)$ & & $(0.306)$ \\
\hline Superficial $\left(\mathrm{T}_{\mathrm{a}}-\mathrm{T}_{1 \mathrm{a}}\right)$ & $76.6 \pm 1.8$ & & $14.7 \pm 1.3$ & & $5.3 \pm 0.4$ & & $14.4 \pm 1.1$ & & $55.6 \pm 1.6$ & & $14.3 \pm 1.1$ & \\
\hline Invasive $\left(\mathrm{T}_{1 \mathrm{~b}}-\mathrm{T}_{4}\right)$ & $39.8 \pm 2.1$ & & $22.0 \pm 1.5$ & & $6.1 \pm 0.4$ & & $16.1 \pm 1.0$ & & $52.3 \pm 1.6$ & & $15.8 \pm 1.1$ & \\
\hline
\end{tabular}

${ }^{\mathrm{a}}$ The expression for each gene was determined by immunohistochemical analysis in tissue microarray and represents the mean value of REL \pm standard deviation.

${ }^{\mathrm{b}}$ Wilcoxon's rank sum test.

${ }^{\mathrm{c}}$ Histologic grading is according to WHO grading system for bladder tumors. Tumors were divided into two groups designated as of low histologic grade (combined grade 1 and 2) and of high histologic grade corresponding to grade 3 tumors.

${ }^{d}$ Staging is according to the TNM classification of malignant tumors with $\mathrm{T}_{1 \mathrm{a}}-\mathrm{T}_{1 \mathrm{~b}}$ substaging. Tumors were divided into two groups designated as superficial $\left(\mathrm{T}_{\mathrm{a}}-\mathrm{T}_{1 \mathrm{a}}\right)$ and invasive $\mathrm{T}_{1 \mathrm{~b}}-\mathrm{T}_{4}$.

stromal invasion. The immunohistochemical staining patterns for $C D H 1$ and normal urothelium and two major subsets of bladder tumors corresponding to low-grade papillary TCC and high invasive nonpapillary TCC are shown in Figure 5. Reduced expression of $\mathrm{CDH} 1$ and high expression of TOP2A was associated with increased propensity for distant metastasis and decreased 5-year and overall survival (Table 2).

By using the immunohistochemical expression levels of six genes, we were able to classify the tumors into two major groups (Figure 6a). The first group (cluster A) consisted of predominantly lowgrade superficial papillary carcinomas characterized by the low expression of TOP2A, FN1, MMP7, $M M P 12, C D C 2$, and the high expression of $C D H 1$. The second group (cluster B) consisted predominantly of high-grade bladder carcinomas characterized by the reduced expression of $C D H 1$ and the increased expression of the remaining five genes. These clusters did not, however, correlate well with the clinical behavior of tumors (Tables 2 and 3). In order to identify the combination of genes whose expression levels could be used to identify aggressive forms of bladder cancer, we performed additional cluster analyses using only those genes whose expressions correlated individually with at least some predictors of clinical behavior. Using this approach, we identified that the combined use of CDH1 and TOP2A expression levels can be used to classify tumors into two groups that correlated well with more and less aggressive forms of bladder cancer (Figure 6b). Tumors characterized by the high expression of TOP $2 A$ and the reduced expression of $C D H 1$ displayed increased propensity for distant metastasis and were associated with the decreased metastasis-free and overall survival as compared to those tumors that showed low expression of TOP2A and high expression level of $C D H 1$ (Figure 7). The relationship of these parameters with clinical aggressiveness was evident in both Kaplan-Meier and Cox proportional hazard analysis (Tables 2 and 3 ). The predictions of adverse clinical outcome based on the expression levels of $C D H 1$ and TOP2A were as strong as those based on the conventional clinicopathological parameters such as histologic grade of the tumor and stage of the disease (Tables 4 and 5).

\section{Discussion}

Our analysis of gene expression profiles in the urothelium adjacent to tumors showed that the alterations in gene clusters involved in the transcription process underlie the development of bladder cancer from intraurothelial preneoplastic conditions. There was a remarkable similarity between the expression profiles for the tumors developing via papillary and nonpapillary pathways, implying that such alterations represent a common theme of bladder carcinogenesis. Out of seven clusters that showed an altered expression profile in bladder tumors and their adjacent urothelium, only 68 genes showed differential expression in the low-grade superficial papillary tumors and high-grade invasive nonpapillary carcinomas. The cluster of 68 genes differentially expressed between the two major pathogenetic subsets of bladder tumors coded primarily for proteins involved in cell stroma interactions. The high-grade invasive tumors were characterized by increased expression of genes coding for proteins responsible for stromal 


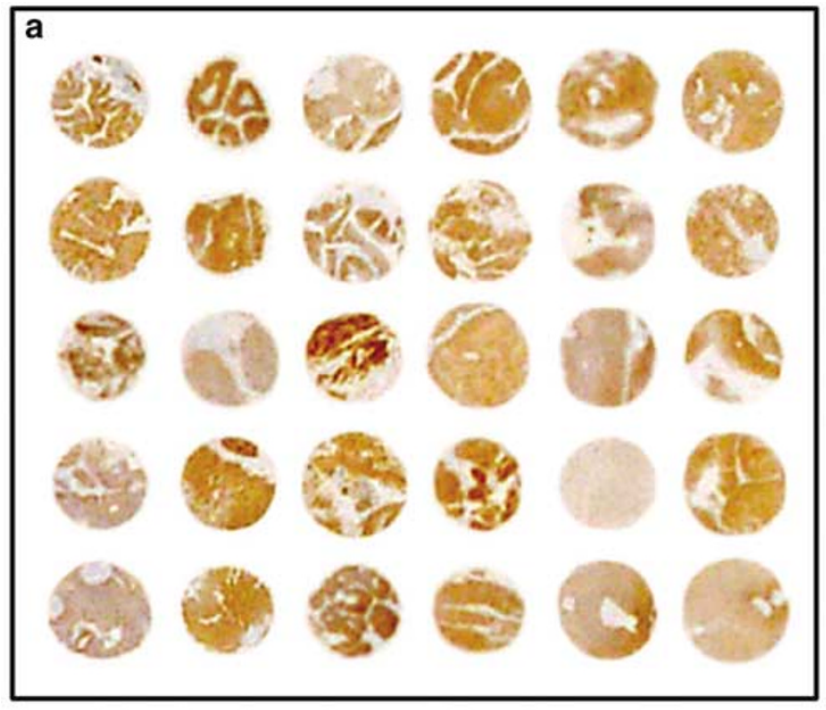

d
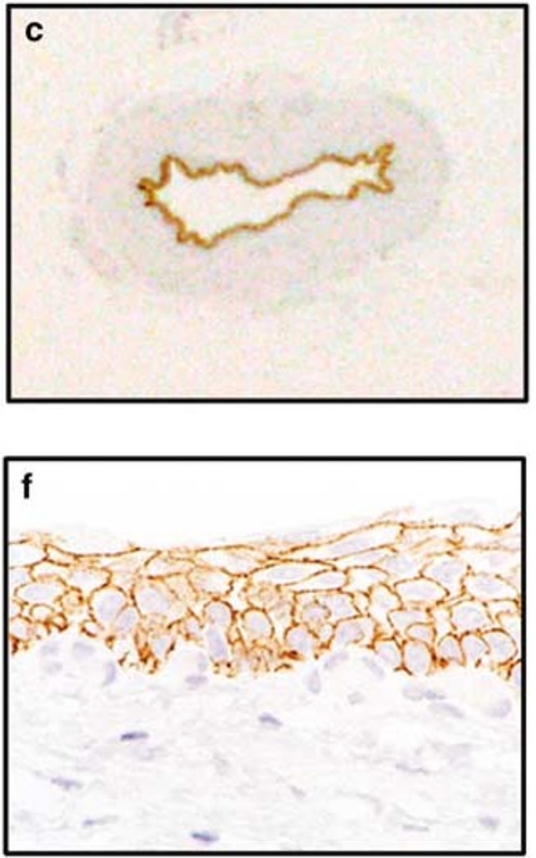
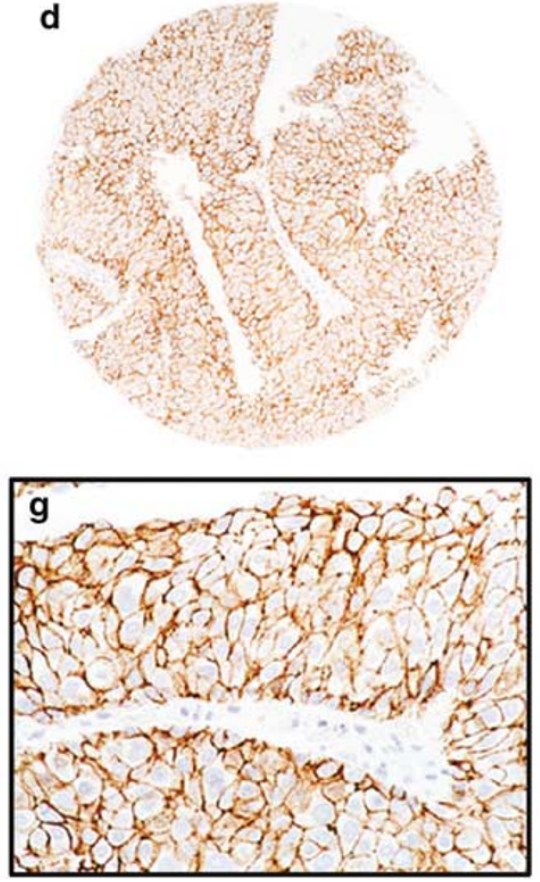

b

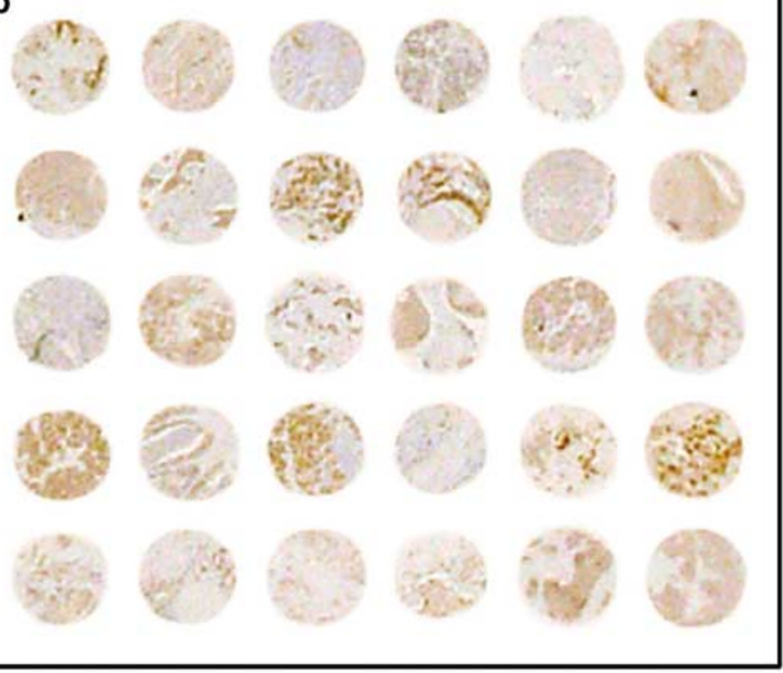

e

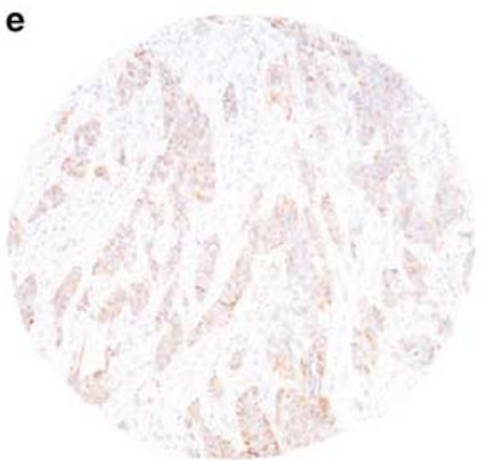

Figure 5 Expression of e-cadherin ( $C D H 1$ ) tested in a tissue microarray containing samples of 251 bladder tumors. (a) Low-power view of representative tissue cores corresponding to low-grade (Grade 1-2) superficial $\left(\mathrm{T}_{\mathrm{a}}-\mathrm{T}_{1 \mathrm{a}}\right)$ papillary TCCs. (b) Low-power view of representative tissue cores corresponding to high-grade (Grade 3) invasive $\left(\mathrm{T}_{1 \mathrm{~b}}-\mathrm{T}_{4}\right.$ ) TCC. (c and d) Baseline expression levels in normal urothelium. (e and f) Expression levels in low-grade superficial papillary TCC. (g and $\mathbf{h}$ ) Expression levels in high-grade invasive TCC. Note that expression level of e-cadherin in low-grade superficial TCCs is similar to its baseline expression in normal urothelium. A decreased level of e-cadherin expression is seen in a large proportion of high-grade invasive TCCs.

degradation such as MMP7, MMP12, and CTSE or for proteins such as FN1 involved in the promotion of invasive growth. These tumors were also characterized by a downregulation of genes coding for cell adhesion proteins such as cadherins. The expression profile of these genes was altered not only in tumor but also in adjacent urothelium. Therefore, the signature expression profiles of the tumor could be detected in the intraurothelial occult phase of bladder neoplasia. When six representative genes showing differential expression in major patho- genetic pathways of bladder carcinogenesis were tested on tissue microarrays, the bladder tumors were separated into two groups corresponding in general to low-grade superficial tumors and highgrade invasive carcinomas. The classification of bladder tumors based on the combined use of six genes did not, however, correlate well with their clinical behavior. In contrast the expression levels of two genes only (CDH1 and TOP2A) could be used to predict adverse clinical outcomes of patients with bladder cancer. Tumor characterized by the high 
Table 2 Summary of Kaplan-Meier analyses of the suitability of expression levels of six genes and pathologic features as predictors of recurrence, metastasis, and survival in patients with bladder cancer $(n=251)$

\begin{tabular}{|c|c|c|c|c|c|c|}
\hline & \multicolumn{2}{|c|}{ Recurrence-free } & \multicolumn{2}{|c|}{ Metastasis-free } & \multicolumn{2}{|c|}{ Overall-survival } \\
\hline & Patients (\%) & $\mathrm{P}$-value* & Patients(\%) & $\mathrm{P}$-value* & Patients (\%) & P-value* \\
\hline CDH1 $1^{\text {a }}$ (low expression) & & 0.87 & & 0.01 & & 0.01 \\
\hline Low & 8 & & 21 & & 24 & \\
\hline High & 11 & & 49 & & 48 & \\
\hline FN1 ${ }^{\text {a }}$ (high expression) & & 0.89 & & 0.2 & & 0.29 \\
\hline Low & 4 & & 28 & & 30 & \\
\hline High & 9 & & 30 & & 31 & \\
\hline TOP $2 A^{\text {a }}$ (high expression) & & 0.1 & & 0.01 & & 0.01 \\
\hline Low & 9 & & 45 & & 48 & \\
\hline High & 7 & & 29 & & 29 & \\
\hline$C D C 2^{\mathrm{a}}$ & & 0.91 & & 0.3 & & 0.58 \\
\hline Low & 7 & & 35 & & 36 & \\
\hline High & 8 & & 36 & & 39 & \\
\hline$M M P 7^{\mathrm{a}}$ & & 0.48 & & 0.99 & & 0.95 \\
\hline Low & 0 & & 25 & & 27 & \\
\hline High & 12 & & 41 & & 43 & \\
\hline$M M P 12^{\mathrm{a}}$ & & 0.12 & & 0.25 & & 0.29 \\
\hline Low & 18 & & 42 & & 45 & \\
\hline High & 3 & & 28 & & 29 & \\
\hline Cluster $A$ vs $B^{\mathrm{b}}$ & & 0.6 & & 0.1 & & 0.08 \\
\hline Cluster A & 19 & & 25 & & 17 & \\
\hline Cluster B & 11 & & 13 & & 11 & \\
\hline CDH1+TOP2A (Cluster D, CDH1 high and TOP2A low) & & 0.1 & & 0.01 & & 0.01 \\
\hline Cluster C & 15 & & 39 & & 42 & \\
\hline Cluster D & 48 & & 81 & & 81 & \\
\hline Histologic grade (low (Grade 1-2) vs high (Grade 3)) & & 0.97 & & 0.01 & & 0.01 \\
\hline Low grade & 6 & & 59 & & 59 & \\
\hline High grade & 12 & & 20 & & 21 & \\
\hline Growth pattern (papillary vs nonpapillary) & & 0.58 & & 0.01 & & 0.01 \\
\hline Papillary & 11 & & 12 & & 13 & \\
\hline Nonpapillary & 17 & & 52 & & 52 & \\
\hline Invasion (superficial $\left(T_{a}-T_{1 a} \text { ) vs invasive }\left(T_{1 b}-T_{4}\right)\right)^{e}$ & & 0.64 & & 0.01 & & 0.01 \\
\hline Superficial & 8 & & 70 & & 55 & \\
\hline Invasive & 11 & & 29 & & 15 & \\
\hline
\end{tabular}

${ }^{*} P$-values of Kaplan-Meier log-rank test.

${ }^{\mathrm{a}}$ The expression for each gene was determined by immunohistochemical analysis in tissue microarray and represents the comparison between the tumor groups expressing low and high level of the gene with the median value of REL differentiating low and high expression levels.

${ }^{\mathrm{b}}$ Clusters A and B were defined on the basis of differential expressions of six genes in tissue microarray as depicted in Figure 6a.

${ }^{\mathrm{C}}$ Using immunohistochemical expression levels of CDH1 and TOP2A tumors were classified into two groups-(C) characterized by high expression levels of CDH1 and low expression levels of TOP2A and (D) characterized by overexpression of TOP2A and low expression of CDH1 as shown in Figure 6b.

${ }^{\mathrm{d}}$ Histologic grading was performed according to WHO grading system for bladder tumors.

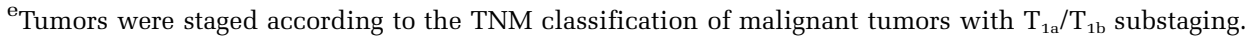

The feature that correlates with aggressive clinical behavior is shown in parentheses.

expression of TOP2A and reduced expression of $C D H 1$ showed high propensity for distant metastatsis and were associated with the decrease of metastasis-free and overall survival of patients with bladder cancer.

Molecular data and numerous clinical studies indicate that alterations in both the $p 53$ and $R B$ cell cycle regulatory pathways involving either direct alterations of the p53 and $R B 1$ genes or loss of the randomly linked CDKN2a (p16ink4a) and $A R F$ ( 1 19ink4a) genes play a major role in human bladder carcinogenesis. $^{21}$ Alterations of the p53 and $R B$ regulatory pathways are predominantly seen in clinically aggressive high-grade bladder cancer. $^{22-28}$ 


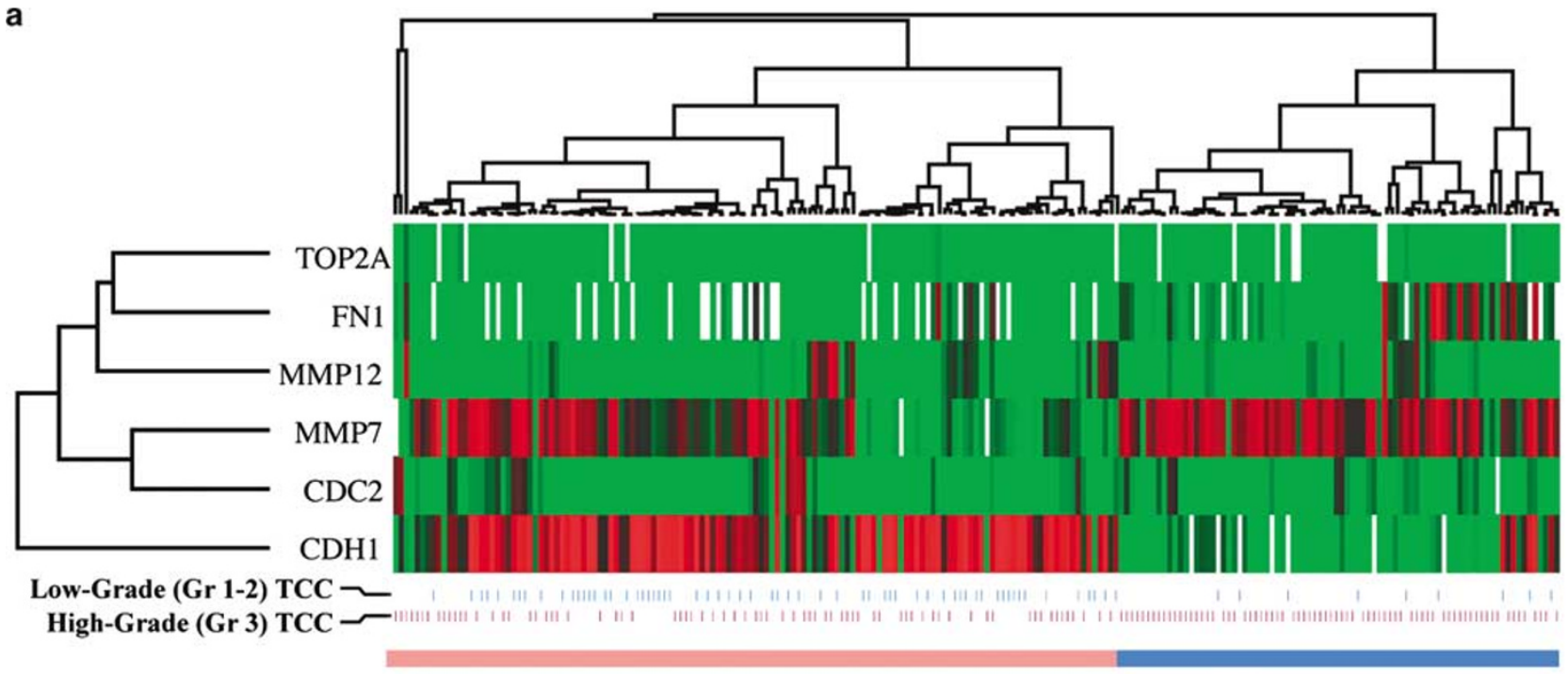

Cluster A

Cluster B

b

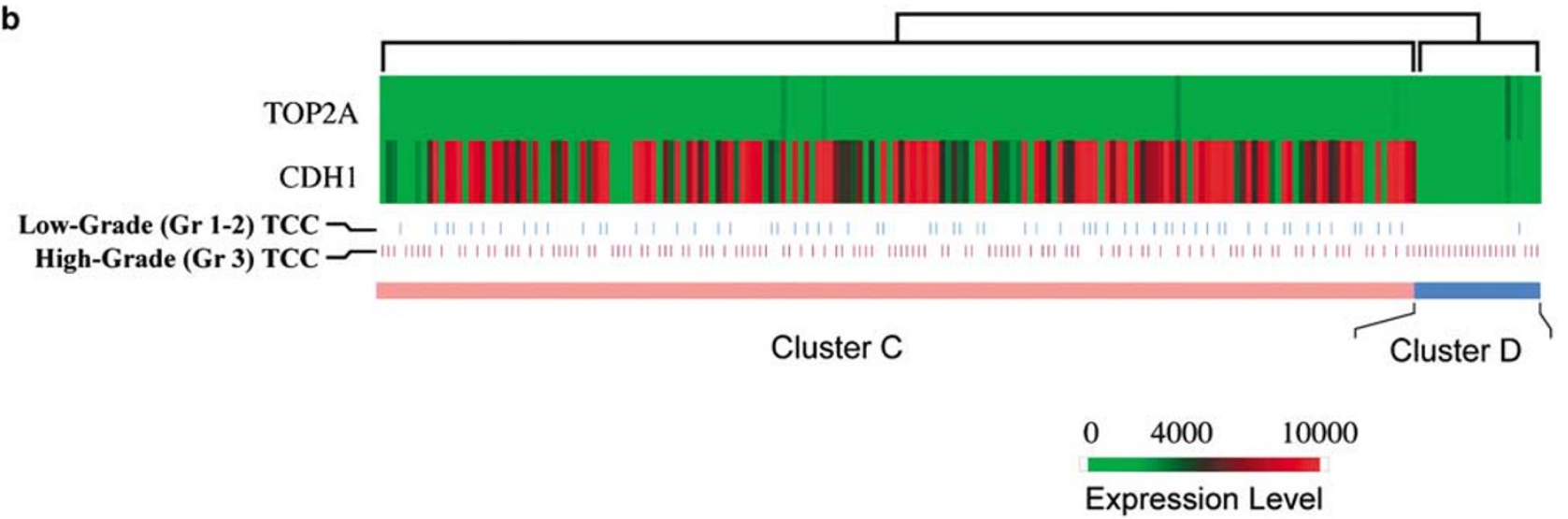

Figure 6 Two-way hierarchical clustering analysis of 251 bladder tumor samples based on immunohistochemical expression levels of genes differentially expressed in low-grade (Grade 1-2) superficial $\left(\mathrm{T}_{\mathrm{a}}-\mathrm{T}_{1 \mathrm{a}}\right)$ papillary TCCs and high-grade (Grade 3 ) invasive $\left(\mathrm{T}_{1 \mathrm{~b}}-\mathrm{T}_{4}\right)$ nonpapillary TCCs identified by cDNA microarray analysis. (a) Clustering analysis based on expression levels of six genes. Immunohistochemically revealed expression levels of six genes (TOP2A, FN1, MMP7, MMP12, CDC2, and CDH1) can be used to separate the majority of tumors into two groups, one corresponding in general to low-grade superficial papillary TCCs (cluster A) and the other to high-grade invasive nonpapillary TCCs (cluster B). (b) Clustering analysis based on expression levels of two genes (TOP2A and CDH1). Similar to the clustering analysis shown in (a), the expression levels of TOP2A and CDH1 separate bladder tumors into two groups. The first group (cluster $\mathrm{C}$ ) is characterized by the high expression levels of $C D H 1$ and the low expression levels of TOP2A. The second group (cluster D) is characterized by the low expression levels of $C D H 1$ and the high expression levels of TOP2A. The genes are listed on the left side of the diagrams. The hierarchical clustering of individual tumor samples based on the expression levels of immunohistochemically stained genes is shown at the top of the diagram. The expression levels are shown by the color saturation scale. High expression is identified by red while the low expression is depicted as green. The absence of data on immunohistochemical staining due to the detachment of individual tissue cores are inconclusive immunohistochemical results depicted in white.

The loss of function of these key tumor suppressors in bladder carcinogenesis is related to point mutations, which typically do not affect their expression levels. Thus, the alterations of $p 53$ and $R B 1$ could not be effectively analyzed by cDNA microarrays used in our study.

The human ras genes represent an important prototypical family of cellular transforming genes originally identified in the T24 human urothelial cancer cell line. ${ }^{29}$ Two mechanisms for ras gene transformation have been discovered.
The most frequent is mutation of codons $12,13,59$, or 61, which affect the enzymatic activity of the protein. In the second mechanism, internal splicing within the last intron mediates ras gene expression. Mutations of the coding sequence of the H-ras gene, especially at codon 12, are relatively frequent, appearing in approximately $30-40 \%$ of urothelial malignancies. ${ }^{30}$ Although concurrent mutations within the splicing mechanism and the coding sequence resulting in the overexpression of the transforming gene product were found exclusively 
Table 3 Univariate Cox proportional hazard model assessing the relation of expression levels of six genes to the time between diagnosis and recurrence, metastasis, and overall survival

\begin{tabular}{|c|c|c|c|}
\hline & Recurrence free* & Metastasis free* & Overall survival* \\
\hline CDH1 (low expression) a & 0.79 & $<0.01$ & $<0.01$ \\
\hline$F N 1^{*}$ & 0.89 & 0.19 & 0.21 \\
\hline TOP2A (high expression) $)^{a}$ & 0.08 & 0.02 & 0.02 \\
\hline$C D C 2^{a}$ & 0.57 & 0.21 & 0.28 \\
\hline$M M P 7^{a}$ & 0.58 & 0.91 & 0.81 \\
\hline$M M P 12^{a}$ & 0.07 & 0.25 & 0.19 \\
\hline Clusters A vs B (Cluster B) ${ }^{\mathrm{b}}$ & 0.06 & $<0.01$ & 0.08 \\
\hline TOP $2 A+C D H 1$ (Cluster D, $C D H 1$ high and TOP $2 A$ low) ${ }^{\mathrm{C}}$ & 0.03 & $<0.01$ & $<0.01$ \\
\hline
\end{tabular}

${ }^{*} P$-values are from likelihood ratio tests for the Cox models.

${ }^{\mathrm{a}}$ The expression for each gene was determined by immunohistochemical analysis in tissue microarray and represents the comparison between the tumor groups expressing low and high level of the gene with the median value of REL differentiating low and high expression levels. REL was calculated by optical densitometry as described in experimental procedures. The expression level that correlates with aggressive clinical behavior is depicted in parentheses.

${ }^{\mathrm{b}}$ Clusters $\mathrm{A}$ and $\mathrm{B}$ were defined on the basis of differential expressions of 6 genes in tissue microarray as depicted in Figure 6a.

${ }^{\mathrm{C}}$ Using immunohistochemical expression levels of $C D H 1$ and TOP2A, tumors were classified into two groups-(C) characterized by high expression levels of $C D H 1$ and low expression levels of TOP2A and (D) characterized by overexpression of TOP2A or low expression of $C D H 1$ as shown in Figure $6 b$.

Table 4 Summary of Kaplan-Meier analyses showing estimates and 95\% confidence intervals for proportions of patients surviving free of metastasis at 1,3 , and 5 years after diagnosis by tumor grade, stage and combined immunohistochemical expression levels of $C D H 1$ and TOP $2 A$

\begin{tabular}{|c|c|c|c|c|c|c|}
\hline & \multicolumn{6}{|c|}{ Years after diagnosis } \\
\hline & \multicolumn{2}{|c|}{1} & \multicolumn{2}{|c|}{3} & \multicolumn{2}{|c|}{5} \\
\hline & $(\%)^{\mathrm{a}}$ & P-value* & $(\%)^{\mathrm{a}}$ & $\mathrm{P}$-value* & $(\%)^{\mathrm{a}}$ & P-value* \\
\hline Histologic grade $e^{\mathrm{b}}$ & & $<0.0001$ & & $<0.0001$ & & $<0.0001$ \\
\hline Low grade (Gr. 1-2) & 93 (87.99) & & $81(73.91)$ & & $73(63.84)$ & \\
\hline High grade (Gr. 3) & $66(58.75)$ & & $40(32.50)$ & & $33(25.43)$ & \\
\hline Stage $^{\mathrm{c}}$ & & $<0.0001$ & & $<0.0001$ & & $<0.0001$ \\
\hline Superficial $\mathrm{T}_{\mathrm{a}}-\mathrm{T}_{1 \mathrm{a}}$ & $90(84.96)$ & & $74(66.84)$ & & $68(58.78)$ & \\
\hline Invasive $\mathrm{T}_{1 \mathrm{~b}}$-and higher & $64(55.73)$ & & $38(29.49)$ & & $29(21.40)$ & \\
\hline CDH1 and TOP $2 A$ expression ${ }^{\mathrm{d}}$ & & 0.0051 & & 0.0035 & & 0.0009 \\
\hline CDH1 high and TOP2A low & $91(84.100)$ & & $78(67.71)$ & & 78 (67.91) & \\
\hline CDH1 low or TOP2A high & $69(61.78)$ & & $44(36.54)$ & & $35(27.45)$ & \\
\hline
\end{tabular}

${ }^{*} P$-value of two sided log-rank test.

${ }^{a}(\%)$ Proportion of patients surviving free of metastasis. The $95 \%$ confidence interval for lower and upper bounds are shown in parentheses.

${ }^{\mathrm{b}}$ Histologic grading is according to WHO grading system for bladder tumors. Tumors were divided into two groups designated as of low histologic grade (combined Grade 1 and 2) and of high histologic grade corresponding to grade 3 tumors.

${ }^{\mathrm{c}}$ Staging is according to the TNM classification of malignant tumors with $\mathrm{T}_{1 \mathrm{a}}-\mathrm{T}_{1 \mathrm{~b}}$ substaging. Tumors were divided into two groups designated as superficial $\left(\mathrm{T}_{\mathrm{a}}-\mathrm{T}_{1 \mathrm{a}}\right)$ and invasive $\left(\mathrm{T}_{1 \mathrm{~b}}-\mathrm{T}_{4}\right)$.

${ }^{\mathrm{d}}$ Using immunohistochemical expression levels of $C D H 1$ and TOP2A tumors were classified into two groups. The first group was characterized by high expression levels of $C D H 1$ and low expression levels of TOP $2 A$. The second group was characterized by high expression levels of $T O P 2 A$ or low expression levels of $C D H 1$ as shown in Figure $6 \mathrm{~b}$.

in high-grade and high-stage tumors, they could be documented in less than $10 \%$ of urothelial tumors. Since the activation of H-ras in bladder carcinogenesis is primarily by point mutations, which do not alter significantly its expression, we could not detect the direct involvement of this gene by the technology used in our study. However, the upregulation of KRAS2, MAP2K3, and $R A B 9$ was consistent with the ras pathway activation.
More recent studies on the development of bladder preneoplasia provide evidence that some early molecular events are common for both pathogenetic pathways (papillary and nonpapillary). These events precede the development of even microscopically recognizable disease and are antecedent to the involvement of major known tumor suppressors such as $R B 1$ and $p 53 .^{31-35}$

Although cDNA microarrays could not detect any direct involvement of RB1 and p53 in 
546
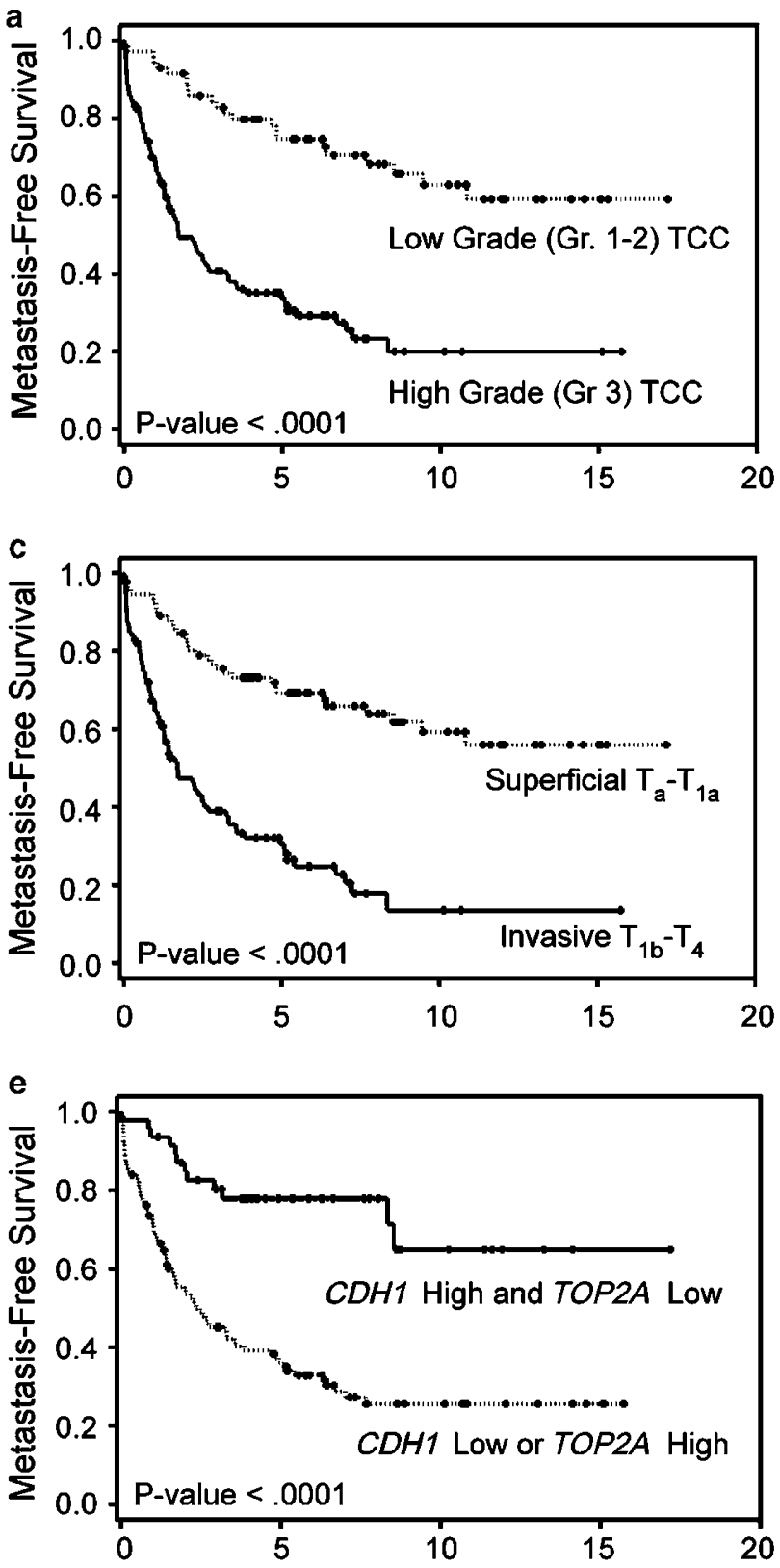
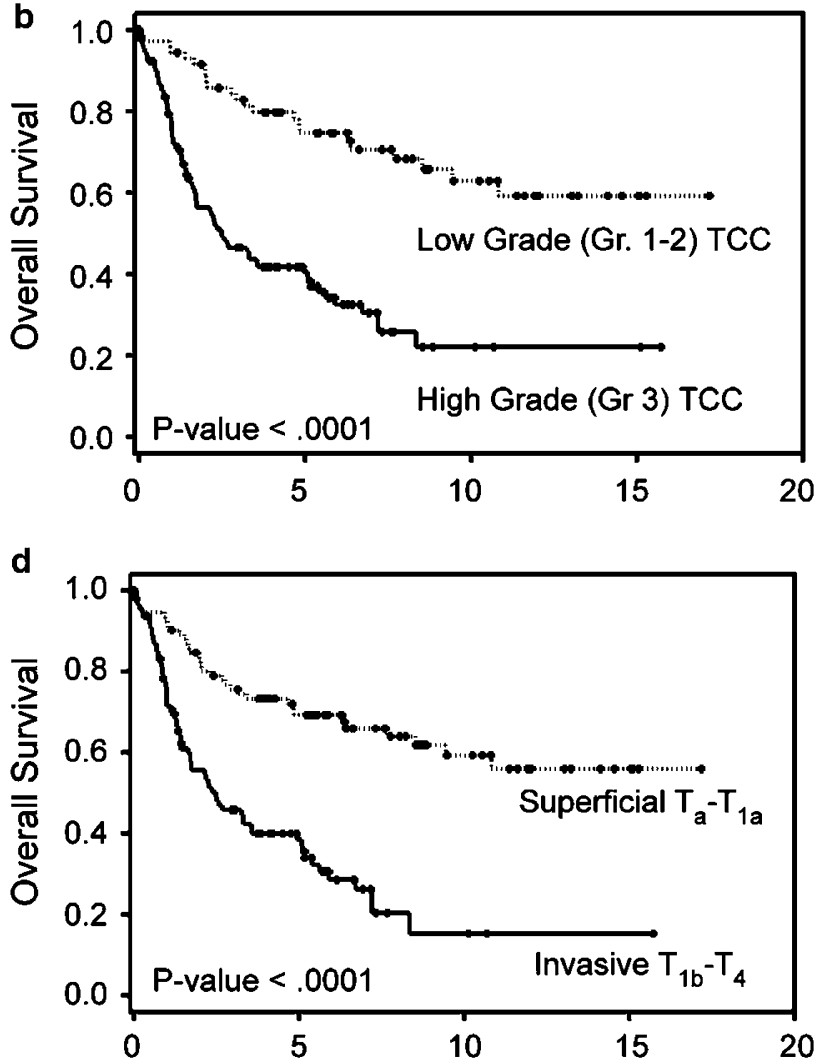

f

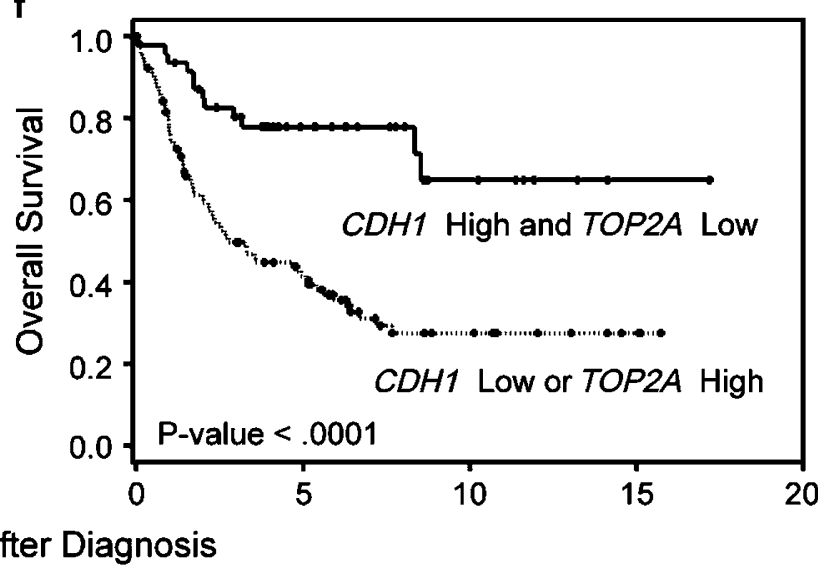

Figure 7 Kaplan-Meier plots showing metastasis-free and overall survival of 251 patients with bladder cancer stratified by tumor grade, stage and by their immunohistochemical expression levels of $C D H 1$ and TOP2A measured in tissue microarrays. (a and b) Metastasis-free and overall survival by tumor grade stratified as low grade (Grade 1-2) and high grade (Grade 3). (c and d) Metastasis-free and overall survival by stage of the disease stratified as superficial (stage $\mathrm{T}_{\mathrm{a}}-\mathrm{T}_{1 \mathrm{a}}$ ) and invasive (stage $\mathrm{T}_{1 \mathrm{~b}}-\mathrm{T}_{4}$ ). (e and f) Metastasis-free and overall survivals by the joint immunohistochemical expression levels of CDH1 and TOP2A. The first group is characterized by the highexpression level of CDH1 and low-expression levels of TOP2A. The second group is characterized by the low-expression levels of CDH1 and the high-expression levels of TOP2A. Point estimates for 1st, 3rd, and 5th year after diagnosis and their respective 95\% confidence intervals for proportions of patients surviving free of metastasis and for overall survival are provided in Tables 4 and 5 .

bladder cancer, they did identify clusters of genes, unique to subgroups of tumors such as superficial $\left(\mathrm{T}_{\mathrm{a}}-\mathrm{T}_{1 \mathrm{a}}\right)$ or invasive $\left(\mathrm{T}_{1 \mathrm{~b}}-\mathrm{T}_{4}\right)$ tumors. ${ }^{36}$ The alteration of a cell adhesion cluster characteristic of invasive tumors is particularly important and has been identified by prior cDNA microarray studies. ${ }^{36-38}$
The role of fibroblast growth factor receptors (FGFRs) in bladder cancer-associated angiogenesis has been recently extensively studied. ${ }^{39}$ It appears that some of those receptors (FGFR3) can be mutated while others (FGFR1 and 2) show abnormal expression levels. The identification of overexpressed FGFR4 in our study provides additional information 
Table 5 Summary of Kaplan-Meier analyses showing estimates and 95\% confidence intervals for proportions of patients surviving at 1 , 3 , and 5 years after diagnosis by tumor grade, stage and combined expression levels of CDH1 and TOP2A

\begin{tabular}{|c|c|c|c|c|c|c|}
\hline & \multicolumn{6}{|c|}{ Years after diagnosis } \\
\hline & \multicolumn{2}{|c|}{1} & \multicolumn{2}{|c|}{3} & \multicolumn{2}{|c|}{5} \\
\hline & $(\%)^{\mathrm{a}}$ & $\mathrm{P}^{*}$ & $(\%)^{\mathrm{a}}$ & $\mathrm{P}^{*}$ & $(\%)^{\mathrm{a}}$ & $\mathrm{P}^{*}$ \\
\hline Histologic grade ${ }^{\mathrm{b}}$ & & 0.0005 & & $<0.0001$ & & $<0.0001$ \\
\hline Low grade (Gr. 1-2) & 93 (87.99) & & $81(72.90)$ & & $73(62.84)$ & \\
\hline High grade (Gr. 3) & $72(64.80)$ & & $46(37.55)$ & & $39(30.48)$ & \\
\hline Stage $^{\mathrm{c}}$ & & 0.0003 & & $<0.0001$ & & $<0.0001$ \\
\hline Superficial $\mathrm{T}_{\mathrm{a}}-\mathrm{T}_{1 \mathrm{a}}$ & $90(84.96)$ & & $74(65.83)$ & & $68(58.78)$ & \\
\hline Invasive $\mathrm{T}_{1 \mathrm{~b}}$ and higher & $70(62.79)$ & & $45(35.55)$ & & $37(27.47)$ & \\
\hline CDH1 and TOP $2 A$ expression ${ }^{\mathrm{d}}$ & & 0.0089 & & 0.0208 & & 0.0076 \\
\hline CDH1 high and TOP2A low & $92(84.100)$ & & 78 (67.91) & & $78(67.91)$ & \\
\hline CDH1 low and TOP2A high & $75(67.83)$ & & 49 (40.59) & & $40(32.51)$ & \\
\hline
\end{tabular}

${ }^{*} P$-value of two sided log-rank test.

${ }^{a}(\%)$ Proportion of patients surviving at a given point. The 95\% confidence interval lower and upper bounds are shown in parentheses.

${ }^{\mathrm{b}}$ Histologic grading is according to WHO grading system for bladder tumors. Tumors were divided into two groups designated as of low histologic grade (combined Grade 1 and 2) and of high histologic grade corresponding to Grade 3 tumors.

${ }^{\mathrm{c}}$ Staging is according to TNM classification of malignant tumors with $\mathrm{T}_{1 \mathrm{a}}-\mathrm{T}_{1 \mathrm{~b}}$ substaging. Tumors were divided into two groups designated as superficial $\left(\mathrm{T}_{\mathrm{a}}-\mathrm{T}_{1 \mathrm{a}}\right)$ and invasive $\left(\mathrm{T}_{1 \mathrm{~b}}-\mathrm{T}_{4}\right)$.

${ }^{\mathrm{d}}$ Using immunohistochemical expression levels of $C D H 1$ and TOP2A, tumors were classified into two groups. The first group was characterized by the high expression levels of $C D H 1$ and low expression levels of TOP2A. The second group was characterized by high expression levels of TOP2A or low expression levels of $C D H 1$ as shown in Figure 6b.

on the involvement of this class of genes in bladder carcinogenesis. Prior studies documented that mutations and overexpression of FGFR4 are associated with progression and aggressive clinical behavior of several epithelial and soft tissue malignancies. ${ }^{40-42}$

In summary, our study showed that the alterations of gene clusters involved in the transcriptional regulation of proliferation, differentiation, and programmed cell death underlie the development of bladder cancer. Such alterations represent a unifying theme of papillary and nonpapillary pathways of bladder cancer development and were detected not only in clinically evident tumors but also in their adjacent urothelium. This observation implies that such changes occurred in the intraurothelial preneoplastic phase of bladder neoplasia. In fact, they are keeping with our previously published observations indicating that both pathways (ie papillary and nonpapillary) of bladder carcinogenesis start as clonal expansions of phenotypically normal urothelial cells. ${ }^{32-35}$ Clones involving large areas of bladder mucosa accompanying both superficial and invasive bladder tumors can be identified in virtually all resected bladders. In this scenario, the continuous growth of such clones results in the formation of superficial low-grade papillary tumors, which may recur but have virtually no potential for invasion or metastasis. The subsequent loss of function of major tumor suppressor genes and alterations of proteins that interact with the stroma appears critical for the development of clinically aggressive form of bladder cancer.

\section{Acknowledgements}

This work was supported by the National Institute of Health, U01 CA85078 (BC), R01 CA066723 (BC), and P50 CA91846 (CD).

\section{References}

1 Albores-Saavedra J. The Pathology of Incipient Neoplasia. Oxford University Press: New York, 2001.

2 Ayala AG, Ro JY, Amin M, et al. Preneoplastic urothelial lesions and urothelial malignancies. In: Henson DE, Albores-Saavedra J (eds). The Pathology of Incipient Neoplasia. Oxford University Press: New York, 2001.

3 Koss LG, Tiamson EM, Robbins MA. Mapping cancerous and precancerous bladder changes. A study of the urothelium in ten surgically removed bladders. JAMA 1974;227:281-286.

4 Gazdar AF, Czerniak B. Filling the void: urinary markers for bladder cancer risk and diagnosis. J Natl Cancer Inst 2001;93:413-415.

5 Jemal A, Tiwari RC, Murray T, et al. Cancer statistics, 2004. CA Cancer J Clin 2004;54:8-29.

6 Koss LG, Nakanishi I, Freed SZ. Nonpapillary carcinoma in situ and atypical hyperplasia in cancerous bladders: further studies of surgically removed bladders by mapping. Urology 1977;9:442-455. 
7 Koss LG, Czerniak B. Image analysis and flow cytometry of tumors of prostate and bladder; with a comment on molecular biology of urothelial tumors. In: Weinstein R, Gardner W (eds). Pathology and pathobiology of the urinary bladder and prostate. Williams \& Wilkins: Baltimore, MD, 1992.

8 Koss LG, Czerniak B. Biology and management of urinary bladder cancer (letter). N Eng J Med 1991;324: 125-126.

9 Czerniak B, Herz F. Molecular biology of common genito-urinary tumors. In: Koss LG (ed). Diagnostic Cytology of the Urinary Tract. Lippincott-Raven: Philadelphia, 1995.

10 Mostofi FK. Histological typing of urinary bladder tumours. In: Mostofi FK, Davis CJ, Sesterhenn IA (eds). Histological typing of urinary bladder tumours. Springer: Berlin, New York, 1999.

11 Sobin LH, Wittekind C. TNM Classification of Malignant Tumors. John Wiley: New York, 1997.

12 Richter J, Jiang F, Gorog JP, et al. Marked genetic differences between stage pTa and stage pT1 papillary bladder cancer detected by comparative genomic hybridization. Cancer Res 1997;57:2860-2864.

13 Sen $\mathrm{S}$, Zhou $\mathrm{H}$, Zhang $\mathrm{RD}$, et al. Amplification/ overexpression of a mitotic kinase gene in human bladder cancer. J Natl Cancer Inst 2002;94: 1320-1329.

$14 \mathrm{Hu} \mathrm{L}$, Cogdell DE, Jia YJ, et al. Monitoring of cDNA microarray with common primer target and hybridization specificity with selected targets. Biotechniques 2002;32:528, 530-532, 534.

15 Kobayashi T, Yamaguchi M, Kim S, et al. Microarray reveals differences in both tumors and vascular specific gene expression in de novo CD5+ and CD5diffuse large B-cell lymphomas. Cancer Res 2003;63: 60-66.

16 Taylor E, Cogdell D, Coombes K, et al. Sequence verification as quality-control step for production of cDNA microarrays. Biotechniques 2001;31:62-65.

17 Baggerly KA, Coombes KR, Hess KR, et al. Identifying differentially expressed genes in cDNA microarray experiments. J Comput Biol 2001;8:639-659.

18 Hsu S-M, Raine L, Fanger H. Use of avidin-peroxidase compelx (APC) in immunoperoxidase techniques: a comparison between APC and unlabeled antibody (PAP) procedures. J Hisochem Cytochem 1981;29: 577-580.

19 Wang T, Wang T, Zhang W, et al. Tissue microarrays: application in neuropathology research, diagnosis and education. Brain Pathol 2002;12:95-107.

20 Hao X, Sun B, Hu L, et al. Distinctive gene and protein espression between primary breast cancers and their lymph node metastases revealed by combined cDNA microarray and tissue microarray. Cancer 2004;100: 1110-1122.

21 Isabel D, Markl J, Peter J. Presence and location of TP53 mutation determines pattern of CDKN2A/ARF pathway inactivation in bladder cancer. Cancer Res 1998;58:5348-5353.

22 Cote RJ, Dunn MD, Chatterjee SJ, et al. Elevated and absent $\mathrm{pRb}$ expression is associated with bladder cancer progression and has cooperative effects with p53. Cancer Res 1998;58:1090-1094.

23 Grossman HB, Liebert M, Antelo M, et al. p53 and RB expression predict progression in T1 bladder cancer. Clin Cancer Res 1998;4:829-834.
24 Dalbagni G, Ren ZP, Herr H, et al. Genetic alterations in tp53 in recurrent urothelial cancer: a longitudinal study. Clin Cancer Res 2001;7:2797-2801.

25 Cordon-Cardo C. p53 and RB: simple interesting correlates or tumor markers of critical predictive nature? J Clin Oncol 2004;22:975-977; Epub 2004 Feb 23.

26 Shariat SF, Tokunaga H, Zhou J, et al. p53, p21, pRB, and p16 expression predict clinical outcome in cystectomy with bladder cancer. J Clin Oncol 2004; 22:1014-1024; Epub 2004 Feb 23.

27 Benedict WF. Altered RB expression is a prognostic clinical marker involved in human bladder tumorigenesis. J Cell Biochem Suppl 1992;16I:69-71.

28 Slaton JW, Benedict WF, Dinney CP. P53 in bladder cancer: mechanism of action, prognostic value, and target for therapy. Urology 2001;57:852-859.

29 Reddy EP, Reynolds RK, Santos E, et al. A point mutation is responsible for the acquisition of transforming properties by the T24 human bladder carcinoma oncogene. Nature 1982;300:149-152.

30 Czerniak B, Cohen GL, Etkind P, et al. Concurrent mutations of coding and regulatory sequences of the Ha-ras gene in urinary bladder carcinomas. Hum Pathol 1992;23:1199-1204.

31 Czerniak B, Li L, Chaturvedi V, et al. Genetic modeling of human urinary bladder carcinogenesis. Genes Chromosomes Cancer 2000;27:392-402.

32 Chaturvedi V, Li L, Hodges S, et al. Superimposed histologic and genetic mapping of chromosome 17 alterations in human urinary bladder neoplasia. Oncogene 1997;14:2059-2070.

33 Czerniak B, Chaturvedi V, Li L, et al. Superimposed histologic and genetic mapping of chromosome 9 in progression of human urinary bladder neoplasia: implications for a genetic model of multistep urothelial carcinogenesis and early detection of urinary bladder cancer. Oncogene 1999;18:1185-1196.

34 Kram A, Li L, Zhang RD, et al. Mapping and genome sequence analysis of chromosome 5 regions involved in bladder cancer progression. Lab Invest 2001;81: 1039-1048.

35 Yoon DS, Li L, Zhang RD, et al. Genetic mapping and DNA sequence-based analysis of deleted regions on chromosome 16 involved in progression of bladder cancer from occult preneoplastic conditions to invasive disease. Oncogene 2001;20:50055014.

36 Dyrskjot L, Thykjaer T, Kruhoffer M, et al. Identifying distinct classes of bladder carcinoma using microarrays. Nat Genet 2003;33:90-96.

37 Sanchez-Carbayo M, Socci ND, Charytonowicz E, et al. Molecular profiling of bladder cancer using cDNA microarrays: defining histogenesis and biological phenotypes. Cancer Res 2002;62:6973-6980.

38 Dyrskjot L, Kruhoffer M, Thykjaer T, et al. Gene expression in the urinary bladder: a common carcinoma in situ gene expression signature exists disregarding histopathological classification. Cancer Res 2004; 64:4040-4048.

39 Munro NP, Knowles MA. Fibroblast growth factors and their receptors in transitional cell carcinoma. J Urol 2003;169:675-682.

40 Morimoto Y, Ozaki T, Ouchida M, et al. Single nucleotide polymorphism in fibroblast growth factor receptor 4 at codon 388 is associated with prognosis in high-grade soft tissue sarcoma. Cancer 2003;98:2245-2250. 
41 Streit S, Bange J, Fichtner A, et al. Involvement of the FGFR4 Arg388 allele in head and neck squamous cell carcinoma. Int J Cancer 2004;111: 213-217.
42 Bange J, Prechtl D, Cheburkin Y, et al. Cancer progression and tumor cell motility are associated with the FGFR4 Arg(388) allele. Cancer Res 2002;62: 840-847.

Supplementary Information accompanies the paper on the Laboratory Investigation website (http:// www.nature.com/labinvest) 